\title{
Research Article \\ Ecological Characterization of the Colonic Microbiota of Normal and Diarrheic Dogs
}

\author{
Julia A. Bell, 1, 2 Jamie J. Kopper, 1, 2,3 Judy A. Turnbull,, 2 Nicholas I. Barbu, 1, 2 \\ Alice J. Murphy, ${ }^{1,2}$ and Linda S. Mansfield ${ }^{1,2,4}$ \\ ${ }^{1}$ Comparative Enteric Diseases Laboratory, National Food Safety and Toxicology Center, Michigan State University, \\ 181 Food Safety Building, East Lansing, MI 48824, USA \\ ${ }^{2}$ College of Veterinary Medicine, Michigan State University, G-100 Veterinary Medical Center, East Lansing, \\ MI 48824, USA \\ ${ }^{3}$ Cell and Molecular Biology Program, Michigan State University, 2240A Biomedical and Physical Science Building, \\ East Lansing, MI 48824, USA \\ ${ }^{4}$ Department of Microbiology and Molecular Genetics, Michigan State University, 2215 Biomedical Physical Sciences, \\ East Lansing, MI 48824, USA
}

Correspondence should be addressed to Linda S. Mansfield, mansfie4@cvm.msu.edu

Received 18 July 2008; Revised 9 October 2008; Accepted 20 November 2008

Recommended by Vincent B. Young

\begin{abstract}
We used terminal restriction fragment polymorphism (T-RFLP) analysis to assess (1) stability of the fecal microbiota in dogs living in environments characterized by varying degrees of exposure to factors that might alter the microbiota and (2) changes in the microbiota associated with acute episodes of diarrhea. Results showed that the healthy canine GI tract harbors potential enteric pathogens. Dogs living in an environment providing minimal exposure to factors that might alter the microbiota had similar microbiotas; the microbiotas of dogs kept in more variable environments were more variable. Substantial changes in the microbiota occurred during diarrheic episodes, including increased levels of Clostridium perfringens, Enterococcus faecalis, and Enterococcus faecium. When diet and medications of a dog having a previously stable microbiota were changed repeatedly, the microbiota also changed repeatedly. Temporal trend analysis showed directional changes in the microbiota after perturbation, a return to the starting condition, and then fluctuating changes over time.
\end{abstract}

Copyright (C) 2008 Julia A. Bell et al. This is an open access article distributed under the Creative Commons Attribution License, which permits unrestricted use, distribution, and reproduction in any medium, provided the original work is properly cited.

\section{INTRODUCTION}

Acute infectious diarrhea is a worldwide public health problem with a long list of differential diagnoses. In the US, major pathogens responsible for most cases include Salmonella, Campylobacter, Shigella, Escherichia coli O157:H7, and Cryptosporidium [1]. Vibrio, Yersinia, Listeria, Cyclospora, Clostridium difficile, Giardia, rotavirus, and Entamoeba histolytica are also reported at lower rates [1]. Enterotoxigenic, enteropathogenic, enteroaggregative, and enteroinvasive strains of E. coli, toxin-producing Clostridium perfringens, Staphylococcus aureus, Bacillus cereus, and norovirus also cause infectious diarrheas, but may not be included in routine testing [1]. Main etiologies for acute diarrhea in the dog are the same or similar to organisms seen in humans [2-6]. Other known pathogens of dogs include Clostridium piliforme [7], Brachyspira (Serpulina) spp. [8], Enterococcus spp. [9], and Helicobacter spp. [1012]. In both humans and dogs, a number of bacteria, such as Enterococcus spp. and certain Clostridia spp., are recognized as opportunistic pathogens or enhance disease from other organisms when conditions are ideal for their growth and when competitors are absent [13-15]. Most cases of acute infectious diarrhea are self-limiting illnesses and resolve in a few days with or without symptomatic treatment with rehydration along with antimicrobial or antiparasitic drugs targeting the "etiological agent" [16]. The presence of known GI tract pathogens recovered or demonstrated is used to attribute an etiology during a diarrheic episode; however, causation is seldom proved.

Few animal models of functional GI disorders exist, but the dog GI tract and microbiota bear many similarities to those of humans. Dogs are monogastric omnivores in which dietary manipulations are easy to achieve and a small-sized 
cecum provides only a small component of hind gut fermentation. Dogs are litter bearers with a short reproductive interval, where families of related individuals are easy to acquire and where management can be manipulated to control environmental exposures. Early work has been done to describe GI microbiota in healthy dogs. Microbial community analysis of feces from 4 Labrador breed dogs was performed using culture followed by $16 \mathrm{~S}$ rRNA gene sequencing [17]. Despite intensive efforts, these methods underestimated community diversity and skewed results toward organisms more successful on particular culture media. These results did support the use of molecularbased methodologies for determining community profiles, but at the time, sequences of many isolates were not found in the Ribosomal Database Project and EMBL databases. Suchodolski et al. described the microbial community in duodenum, jejunum, ileum, and colon contents from six healthy unrelated dogs using near-full-length 16S rRNA gene PCR and cloned libraries [18]. Here, Firmicutes was the most diverse and abundant phylum; Clostridiales was the most diverse bacterial order, forming several Clostridium clusters; anaerobic Fusobacteriales and Bacteroidales increased in their relative abundance along the intestinal tract, peaking in ileum and colon; and Lactobacillales occurred commonly in all parts of the intestine. These results on Firmicutes and Clostridiales were similar in humans [19] with Clostridium cluster XIVa being the predominant contributor to Clostridiales sequences in both dogs and humans. Furthermore, Fusobacteria appeared to be a minor part of the intestinal community in other species, including humans [19]. Also, Proteobacteria-including E. coli-like organismspredominated in the duodenum and were sparse in the colon in both dogs [18] and humans [19]. In another study designed to define host distribution patterns of fecal bacteria of the order Bacteroidales as markers for fecal source identification in aquatic environments, human, dog, cat, and gull sequences were clustered together in phylogenetic analysis [20]. Swanson et al. performed a study using healthy dogs to examine whether prebiotic (fructooligosaccharides) or probiotic (Lactobacillus acidophilus) treatments would alter gut microbial populations, fermentative end products, and nutrient digestibilities [21]. In one experiment, fructooligosaccharide treatment decreased $C$. perfringens and increased fecal butyrate and lactate concentrations, while in a second experiment, this treatment increased bifidobacteria, lactobacilli, and fecal lactate and butyrate and decreased fecal ammonia, isobutyrate, isovalerate, and total branched-chain fatty acid concentrations. Finally, recent global vertebrate gut microbiota studies showed that captive (zoo) bush dogs on carnivorous diets had microbial communities that clustered with other carnivores, and that primates on omnivorous diets had fecal microbiota most like humans [22, 23]. In these studies using tree-based and network-based analyses of microbial communities, clustering by diet (herbivore, omnivore, or carnivore) was highly significant. However, these investigators did not consider the microbiota of modern pet dogs on highly processed diets and cohabiting with humans. Taken together, these studies show that dogs are a reasonable model for study of the role of microbiota in GI disorders and that understanding of the GI microbial community in dogs is at a stage of readiness for this to be pursued.

Many diarrheal diseases are attributable to specific pathogens, to polymicrobial interactions, or to shifts or imbalances in the resident microbial community in response to external stress(s). Thus, acute diarrheas can result from myriad etiologies making attribution difficult. Lately, attention has been focused on the role of the microbiota. The normal gut biota or "enterome" is a complex microbial ecosystem that plays a crucial role in maintaining GI homeostasis and in certain disease states [24]. However, 300-500 different bacterial species are estimated to inhabit the human colon, many of which are not cultivatable [25]. This estimate of diversity has changed little over the years, even with the application of molecular techniques to the study of the colonic microbiota [26, 27]. Eckburg et al. [26] used collector's curves to estimate that extensive sequencing would reveal at least 500 species. Adding to complexity during analysis are the sheer numbers of GI organisms, which can reach a density of $10^{12}$ organisms/gram of feces, with a total gut population of $10^{14}-10^{15}$ microbes [28]. In the dog, breed and age were shown to have significant effects on particular aerobic and anaerobic bacterial counts using denaturing gradient gel electrophoresis of PCR amplified $16 \mathrm{~S}$ ribosomal fragments. Here, each individual dog harbored a characteristic fecal bacterial community which was independent of diet [29]. We hypothesized that dogs have a stable composition of the colon microbial community and that episodes of diarrhea lead to long lasting changes in community composition and/or function; furthermore, treatment for specific pathogens can compound these effects. To address this hypothesis, we required (1) diarrheic perturbations of the GI tract with or without treatment to study, (2) documentation of the presence of pathogens in the GI tract, (3) a costeffective technique for assessing shifts in the GI tract microbiota, and (4) the assurance that the microbiota in an individual is stable enough for us to be able to detect meaningful changes. We used diagnostic PCR assays to document the presence of pathogens in the GI tract. The GI tract perturbations we studied were (1) acute episodes of diarrhea with or without antibiotic treatment and (2) changes in diet and medications. The technique we chose for assessing shifts in the GI tract microbiota was terminal restriction fragment length polymorphism (T-RFLP) analysis.

T-RFLP is one of a family of related techniques used to describe microbial communities containing large numbers of organisms that are undescribed and/or difficult to cultivate. T-RFLP is based on PCR amplification and restriction enzyme digestion of $16 \mathrm{~S}$ rDNA PCR products followed by capillary electrophoresis on a DNA sequencer. Here, data were analyzed using exploratory statistical techniques that help reveal patterns rather than the more familiar inferential statistics that help discriminate between hypotheses. Community studies using these techniques that have been reported to date have involved small numbers of samples. For example, Nielsen et al. characterized populations of 
TABLE 1: Characteristics of dogs enrolled in the study.

\begin{tabular}{|c|c|c|c|c|c|c|c|}
\hline & \multirow{2}{*}{ Breed } & \multirow{2}{*}{ Sex } & \multirow{2}{*}{ Age } & \multicolumn{3}{|c|}{ Diet $(\%)$} & \multirow{2}{*}{ Comments } \\
\hline & & & & protein & fat & fiber & \\
\hline Pet 1 & $\begin{array}{l}\text { Beagle } \times \text { schnauzer; related } \\
\text { to research colony dogs }\end{array}$ & $\mathrm{F}$ & 4 years & 21.5 & 13.0 & 3.0 & $\begin{array}{l}\text { Time series; one diarrheic } \\
\text { samples (dietary } \\
\text { indiscretion; no treatment), } \\
\text { three normal samples }\end{array}$ \\
\hline Pet 2 & $\begin{array}{l}\text { Labrador retriever puppy; } \\
\text { same household as Pet } 1\end{array}$ & M & 9 weeks & 26.0 & 8.5 & 3.0 & $\begin{array}{l}\text { Time series; six normal } \\
\text { samples }\end{array}$ \\
\hline Pet 3 & Golden retriever & M & 12 years & 25.0 & $6.0-8.0$ & 12.0 & $\begin{array}{l}\text { Time series with normal } \\
\text { and diarrheic samples } \\
\text { (dietary indiscretion; } \\
\text { metronidazole treatment) }\end{array}$ \\
\hline Pet 4 & Golden Retriever & M & 6 years & 22.0 & 12.0 & 5.0 & One normal sample \\
\hline Pet 5 & Dachshund & M & 7 years & 22.0 & 13.0 & 3.0 & Normal sample \\
\hline Pet 6 & American Eskimo mix & M & 3 years & 22.0 & 13.0 & 3.0 & Normal sample \\
\hline Pet 7 & Retriever mix & $\mathrm{F}$ & 2 years & ND & ND & ND & Diarrheic sample \\
\hline Pet 8 & Mixed breed & $\mathrm{F}$ & 12 years & ND & ND & ND & Diarrheic sample \\
\hline Research 1 & Beagle $\times$ Schnauzer & $\mathrm{F}$ & 4 years & 25.0 & 9.0 & 5.0 & Normal sample \\
\hline Research 2 & Beagle $\times$ Schnauzer & $\mathrm{F}$ & 6 years & 25.0 & 9.0 & 5.0 & Normal sample \\
\hline Research 3 & Beagle $\times$ Schnauzer & $\mathrm{M}$ & 4 years & 25.0 & 9.0 & 5.0 & Normal sample \\
\hline Research 4 & Beagle $\times$ Schnauzer & $\mathrm{F}$ & 6 years & 25.0 & 9.0 & 5.0 & Normal sample \\
\hline Research 5 & Beagle $\times$ Schnauzer & $\mathrm{F}$ & 4 years & 25.0 & 9.0 & 5.0 & Normal sample \\
\hline
\end{tabular}

lactic acid bacteria and total bacterial communities in one sample each from three colon segments in four human subjects [30]. In this study, the total communities from different parts of the colon in the same individual were similar to each other, but total communities varied between individuals. In another trial, fecal communities were studied in eight individuals of different ages and sexes; five adults and two children had similar arrays of microorganisms in their fecal communities but different proportions of the bacterial species, while a two-week-old infant had a much simpler community [31]. Thus, T-RFLP data revealed valuable results even though attribution of gains or losses of specific bacterial genera or species was not possible. Also, we recognize that many factors may affect the results obtained with the T-RFLP technique; these factors include choice of primers; choice of restriction enzymes; and various amplification biases due to PCR reaction parameters such as amount and complexity of the template DNA, annealing temperature, and number of cycles in the amplification reaction [32-35]. Nevertheless, T-RFLP is rapid, sensitive, and reproducible $[31,34]$, and, unlike many other community analysis techniques, it yields both taxonomic information regarding organisms in the community and estimates of their relative proportions in the total microbial population. It is considered a useful tool in the study of microbial communities and can be used to generate data that help to determine whether further studies employing more precise, laborious, and expensive techniques, such as targeted real-time PCR for the detection and quantization of specific microorganisms or the generation, sequencing, and analysis of cloned $16 \mathrm{~S}$ rDNA libraries, are justified [31].
To address our hypothesis, we studied the microbial communities of dogs during diarrheic episodes and compared them to those of healthy control dogs to make a preliminary assessment of the contribution of members of the normal community to acute diarrheal disease processes. Results of these studies showed that fecal microbiotas varied among dogs, even those that were closely related, and were largely influenced by diet. A dog treated for diarrhea with metronidazole did exhibit loss of richness followed by return to a stable microbiota; the same treatment aimed at a second bout of diarrhea resulted in an unstable microbiota that ultimately lost richness and evenness. Thus, our hypothesis, that dogs have relatively stable colon microbial communities and episodes of diarrhea lead to instability which is compounded by antimicrobial treatments for specific pathogens, can be addressed using these methods particularly if environmental exposures are limited. This work demonstrates that dogs can be used to study changes in microbial communities associated with naturally occurring diarrheas.

\section{MATERIALS AND METHODS}

\subsection{Enrollment of study dogs and experimental design}

We established a standard operating procedure for sample collection and processing that was approved by the Michigan State University Institutional Animal Care and Use Committee (2-16-2006). The study also followed all guidelines and standard protocols of the Michigan State University (MSU) Veterinary Teaching Hospital (VTH). Information on all animals included in the study is given in Table 1. A panel of eight household pet dogs was enrolled in the study 


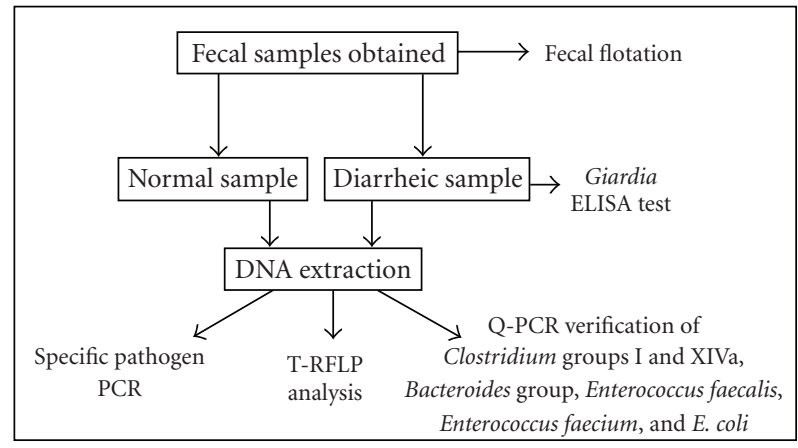

Figure 1: Scheme for sample processing.

over one year. These eight dogs included two pets from a single household (Pets 1 and 2 in Table 1; Pet 1 suffered one episode of diarrhea), a single pet from a second household (Pet 3 in Table 1; this pet suffered two episodes of diarrhea which were treated at the MSU VTH), a single healthy pet from a third household (Pet 4 in Table 1), two healthy pets from a fourth household (Pets 5 and 6 in Table 1), and two pets from different households presenting to the MSU VTH with diarrhea (Pets 7 and 8 in Table 1). Five control dogs from an extended genetically related family were enrolled that were housed in an MSU-closed research colony, were fed the same food daily, and were exercised indoors to prevent infections. Feces were collected from these dogs to assess repeatability and technical quality of our protocols and to provide comparisons to diarrhea cases.

All diagnostic tests (except for an ELISA test for Giardia) and T-RFLP analyses were conducted on DNA isolated from fecal samples. DNA of sufficient quality for T-RFLP analysis could not be isolated from one of two samples from Pet 4 or from Pets 5, 6, 7, or 8. Diagnostic PCR results are presented for all thirteen dogs: T-RFLP results are presented for the five research colony dogs and four household pet dogs (Pets 1, 2, 3 , and 4). For T-RFLP analysis of fecal microbiota over time, we collected repeated fecal samples from three household pet dogs to assess variability of the microbiota based on housing and feeding regimes. As mentioned above, two of these three dogs experienced diarrhea, one of them twice. Therefore, we collected samples from these dogs during and after treatment, if any, with the prescribed antibiotic.

\subsection{History and clinical examination}

The overall strategy for sampling of dogs is shown in Figure 1. The case definition for a dog with diarrhea was a dog that presented with acute diarrhea. If dogs presented to the MSU VTH with diarrhea, we instituted resampling three to five days after completion of treatment. For one of the two diarrheic household pets studied (Pet 3 in Table 1), two original samples were taken before antibiotic treatment and further samples were taken during and after antibiotic treatment; for Pet 1 in Table 1, the initial sample was diarrheic and subsequent samples were taken after resolution of disease, which was not treated.
With cases presenting with signs of acute large bowel diarrhea, the typical MSU small animal clinic protocol includes a fecal flotation, Giardia test, and fecal cytology. Treatment usually comprises a short course of metronidazole (10-50 mg/kg BID) and institution of a low-residue diet. In this study, our protocol involved taking a history, performing a physical examination, and initiating diagnostic tests according to standard methods currently employed in the MSU VTH.

\subsection{Sample handling and DNA isolation}

Preliminary studies were conducted to define the best method of handling fecal samples to optimize T-RFLP analysis. Using clean gloves for each animal, samples from research colony dogs and Pets 1 and 2 were taken as free catch or rectal samples; samples from other dogs were taken from the ground immediately after defecation taking care to avoid taking any part of the sample that touched the ground. Subsamples were taken from the interior of the fecal mass for analysis. The feces was placed into tryptose soy broth with $15 \%$ glycerol, mixed well, aliquoted into at least 4 5 identical subsamples; three were frozen back at -80 and one had DNA extracted that day. Samples were subjected to one of the following treatments: holding on ice only long enough for transport to the laboratory, holding at room temperature for 24 hours prior to DNA extraction, holding on ice for 24 hours prior to DNA extraction, refrigeration for 24 hours prior to DNA extraction, and freezing for 24 hours prior to DNA extraction. These conditions were intended to mimic the possible fates of clinical specimens prior to submission to the laboratory. DNA could be recovered in quantities sufficient for diagnostic PCR and T-RFLP analysis from samples subjected to all treatments, although yields were greater when samples were held on ice only long enough for transport to the laboratory. Freezing was preferred when samples could not be processed immediately in order to avoid changes in microbiota that have been documented in samples held at room or refrigeration temperatures [3638].

Bacterial populations were recovered from $200 \mathrm{mg}$ of feces by suspending samples in $300 \mathrm{mM}$ sucrose solution followed by two low-speed centrifugations as described [39]. Bacteria were then collected by high-speed centrifugation and the pellets resuspended in 200 microliters $10 \mathrm{mM}$ Tris $1 \mathrm{mM}$ EDTA, pH 8.0. Klijn et al. [39] reported that this method results in the recovery of over $80 \%$ of aerobic/facultatively anaerobic bacteria able to grow on Columbia blood agar medium (they did not assay obligately anaerobic bacteria). Similar differential centrifugation methods have been used to isolate bacterial DNA for microbial community analysis from digesta from chicken gastrointestinal tracts $[40,41]$, rat cecal digesta [42], and human feces [43]. Community DNA was isolated from the harvested bacterial cells using QIAgen DNeasy Tissue Kit (QIAgen, Valencia, Calif, USA) according to the manufacturer's instructions for Gram-positive bacteria, including digestion first with $20 \mathrm{mg} / \mathrm{mL}$ lysozyme for one hour at $37^{\circ} \mathrm{C}$ followed by proteinase $\mathrm{K}(20 \mathrm{mg} / \mathrm{mL})$ overnight at $55^{\circ} \mathrm{C}$; 
DNA was then purified from the lysates using QIAgen spin columns.

\subsection{Screening for common pathogens in normal and diarrheic dogs}

Fecal samples were screened for parasites by the CornellWisconsin saturated sucrose flotation technique [44]. Giardia tests were performed using the ProSpect Giardia-ELISAmicroplate assay (Remel, Lenexa, Kan, USA) according to the manufacturer's instructions. DNA preparations were screened for the presence of DNA from the following bacterial pathogens by standard polymerase chain reaction assays using published primer pairs and cycling conditions: Clostridium perfringens [45], Campylobacter spp. [5], Enterococcus spp. [46], Enterococcus faecium [47], Helicobacter spp. [48], Salmonella spp. [49], and Brachyspira (Serpulina) spp. [50]. Purified DNA samples from cultured known bacterial species were used as positive controls for the PCR assays. In addition, quantitative PCR assays (Q-PCR) were performed using primers and cycling conditions developed by Rinttilä et al. [51] for Bacteroides spp. and related organisms, Clostridium group I, and Clostridium group XIVa. However, Q-PCR assays for Escherichia coli were performed as published [52]; Q-PCR assays for Enterococcus faecium, and Enterococcus faecalis were performed as described below [53].

\subsection{T-RFLP analysis}

Terminal restriction fragment polymorphism analysis was conducted using the 516f and 1510r primers, PCR reaction mixture, PCR cycling conditions, and restriction enzyme digestion conditions described by Nagashima et al. [31], except that reactions were carried out using $50 \mathrm{ng}$ template DNA in a total volume of $100 \mu \mathrm{L}$. The forward primer carried a 6-FAM fluorescent probe. The PCR products were purified using QIAquick PCR purification columns (QIAgen; Valencia, Calif, USA) according to the manufacture's protocol prior to digestion with BslI (New England Biolabs, Inc., Ipswich, Mass, USA); the resulting fragments were separated by electrophoresis on an automated DNA sequencer (ABI Prism 3100) at the MSU Genomic Technology Support Facility. An internal lane standard (MapMarker1000; BioVentures, Murfreesboro, Tenn, USA) was added to every sample, and the standard peak sizes were used by the GeneScan Analysis software to compute peak sizes. Electropherograms were stored as computer files for later analysis.

\subsection{T-RFLP data analysis}

Analysis of T-RFLP BslI peak patterns was conducted as follows. Only peaks corresponding to DNA fragment lengths between 100 and $990 \mathrm{bp}$ in length, having a height of at least 25 fluorescent units, and contributing at least $1 \%$ of the total area under the electropherogram were considered; electropherograms having a total area less than 5000 fluorescence units were not analyzed. Likely identities of the phylogenetic groups of bacteria detected were determined manually by comparing peak fragment sizes to fragment sizes assigned to various bacterial groups by Nagashima et al. [31], allowing for an error of $\pm 1 \mathrm{bp}$. Peaks that did not fall into the size classes defined by Nagashima et al. [31] were combined to form an "unknown" class. The identities of the bacterial groups and the range of peak sizes that contributed to each group are shown in Table 2 . The community profile consisted of a list of the bacterial groups present or absent in a sample and the $\%$ area under the electropherogram contributed by each group.

For cluster analysis, the \% area data were fourthroot transformed, and single linkage cluster analysis using the Bray-Curtis similarity index was performed on the transformed data [54]; a dendrogram was constructed, and its stability was evaluated using the jackknife procedure [55]. These calculations were performed using utilities made available online by John Brzustowski at http://www2.biology .ualberta.ca/jbrzusto/cluster.php. The Bray-Curtis similarity index is widely used in community ecology studies because it is less affected than other indices by differences involving rare, low abundance organisms and it is thought to perform better with datasets containing widely differing sets of communities $[55,56]$. This index takes into account both the presence and absence of peaks and differences in the areas under same-sized peaks in the electropherograms, which indicate differences in the proportions of a particular organism in two populations.

We also calculated the descriptive microbial community parameters developed specifically for molecular ecological fingerprinting by Marzorati et al. [57]; the community parameters summarize community richness $\left(R_{0}\right)$, functional organization (Fo, evenness), and dynamics (\% change and $\Delta_{t}$ ). These parameters were calculated and interpreted for T-RFLP profiles generated in this study as described in Marzorati et al. [57], except that the Bray-Curtis similarity index was used in the calculation of the \% change parameter instead of the similarity index used by Marzorati et al. [57]. Finally, patterns of variability in T-RFLP profiles for Pet 3 over time were analyzed by the regression method of Collins et al. [58]. Euclidean distances between microbial communities at different time points were calculated using utilities made available online by John Brzustowski at http://www2 .biology.ualberta.ca/jbrzusto/cluster.php; regression analysis was performed using SigmaStat 3.1 (Systat Software, Point Richmond, Calif, USA).

\subsection{Quantitative real-time PCR method and analyses}

DNA extracted from feces (as previously described) was used as the template in species-specific Q-PCR assays. Bacteroides/Prevotella/Porphyromonas and Clostridium groups I and XIVa assays were performed using the primer sequences from Rinttilä et al. [51]. Escherichia coli Q-PCR assays were performed using primer sequences from Khan et al. [52]; Enterococcus faecalis and Enterococcus faecium Q-PCR assays were performed using primer sequences from Firmesse et al. [53]. In all assays, $25 \mu \mathrm{L}$ reactions were performed in triplicate for each sample with iQ SYBR Green Supermix (Bio-Rad, Hercules, Calif, USA) and 250 ng of fecal DNA. 
TABLE 2: Assignment of T-RFLP fragment size classes to bacterial taxa based on data of Nagashima et al. [31].

\begin{tabular}{|c|c|c|c|}
\hline $\begin{array}{l}\text { Fragment class according to } \\
\text { Nagashima et al. [31] }\end{array}$ & Fragment size range (bp) & Predominant genus & Other genera included \\
\hline BslI 110 & $110-115$ & None & $\begin{array}{l}\text { Clostridium, Eubacterium, } \\
\text { Lactobacillus, Veillonella }\end{array}$ \\
\hline BslI 124 & $125-128$ & Bifidobacterium & None \\
\hline BslI 317 & $316-319$ & Prevotella & Lactobacillus \\
\hline BslI 332 & $326-338$ & Streptococcus & $\begin{array}{l}\text { Bifidobacterium, Clostridium, } \\
\text { Eubacterium, Lactobacillus, } \\
\text { Prevotella }\end{array}$ \\
\hline BslI 370 & $364-378$ & Clostridium & $\begin{array}{l}\text { Bacteroides, Bifidobacterium, } \\
\text { Eubacterium, Lactobacillus, } \\
\text { Prevotella }\end{array}$ \\
\hline BslI 469 & $464-473$ & Bacteroides & Clostridium, Eubacterium, Prevotella \\
\hline BslI 494 & $487-502$ & Clostridium & $\begin{array}{l}\text { Eubacterium, Ruminococcus, } \\
\text { Streptococcus }\end{array}$ \\
\hline BslI 520 & $513-519$ & Enterococcus & $\begin{array}{l}\text { Clostridium, Eubacterium, } \\
\text { Lactobacillus }\end{array}$ \\
\hline BslI 657 & $655-665$ & Lactobacillus; Streptococcus & $\begin{array}{l}\text { Bacteroides, Clostridium, } \\
\text { Enterococcus, Eubacterium, } \\
\text { Ruminococcus }\end{array}$ \\
\hline BslI 749 & $748-757$ & Clostridium & $\begin{array}{l}\text { Eubacterium, Fusobacterium, } \\
\text { Ruminococcus }\end{array}$ \\
\hline BslI 853 & $848-854$ & Bacteroides & Bacteroides \\
\hline BslI 919 & $911-921$ & Ruminococcus & Enterococcus, Eubacterium \\
\hline BslI 940 & $935-941$ & Escherichia & $\begin{array}{l}\text { Clostridium, Eubacterium, } \\
\text { Fusobacterium, Ruminococcus }\end{array}$ \\
\hline BslI 955 & $955-960$ & None & $\begin{array}{l}\text { Clostridium, Eubacterium, } \\
\text { Ruminococcus }\end{array}$ \\
\hline
\end{tabular}

The following cycling protocol was used for Clostridium group I, Clostridium group XIVa, Bacteroides, and E. coli: $95^{\circ} \mathrm{C}$ for 3 minutes and 40 repeats of $95^{\circ} \mathrm{C}$ for 10 seconds, specific annealing temperature for 30 seconds. Cycling parameters for $E$. faecium were $95^{\circ} \mathrm{C}, 3$ minutes; 40 cycles of $63^{\circ} \mathrm{C}$ for 10 seconds. Cycling parameters for E. faecalis were $95^{\circ} \mathrm{C}, 3$ minutes; 40 cycles of $64.5^{\circ} \mathrm{C}$ for 10 seconds. Each species-specific assay was optimized for primer concentration and annealing temperature. Bacteroides species assay used $6.25 \mathrm{pm}$ of each primer per reaction with an annealing temperature of $65^{\circ} \mathrm{C}$. E. coli assays used $6.25 \mathrm{pm}$ of each primer per reaction and an annealing temperature of $63.3^{\circ} \mathrm{C}$. Clostridium Groups I and XIVa used $7.5 \mathrm{pm}$ of each primer per reaction with annealing temperatures of $58.9^{\circ} \mathrm{C}$ and $57^{\circ} \mathrm{C}$, respectively. All Q-PCR assays included a 6-point standard curve in triplicate $\left(R^{2}>0.90\right)$ and three notemplate controls containing all other reaction components on a Bio-Rad iQ5 Real-Time PCR Detection System (BioRad, Hercules, Calif, USA). Three DNA preparations were purchased for the standard curves: Clostridium perfringens for Clostridium group I (Sigma Aldrich, St. Louis, Mo, USA), Ruminococcus productus VPI 4299 for Clostridium group XIVa, and Bacteroides fragilis VPI 2553 (DNA purchased from American Type Culture Collection, Manassas, Va, USA). Three DNA preparations for the standard curves were prepared in our laboratory by the CTAB method of Ausubel et al. [59] from strains E. coli DH5- $\alpha$, Enterococcus faecalis 19433, and Enterococcus faecium 19434.

Bio-Rad iQ5 PCR detection system software (Bio-Rad, Hercules, Calif, USA) was used to calculate the Ct value for each reaction, the mean Ct value for each set of triplicates, and the amount of target DNA using values derived from the standard curves. The statistic PV, which quantifies variability in population abundance over time, was calculated for each of the organisms assayed using the Q-PCR data [60].

\section{RESULTS}

\subsection{Dogs enrolled in study}

Information on sex, age, breed, and diet of all dogs enrolled in the study is given in Table 1. Five control dogs were identified that lived in MSU colonies, were fed the same food daily, and were exercised indoors. These dogs were from a family developed to study an inherited disorder unrelated to the GI tract. As such, dogs were full or half siblings, or their parents. We also collected feces from four normal dogs living in households to assess variability of the microbiota based on housing and feeding regimes. Of the household pets, two were supervised outside (e.g., walked on leash), one was allowed to roam freely in a suburban environment, and one was allowed to roam freely in a rural 


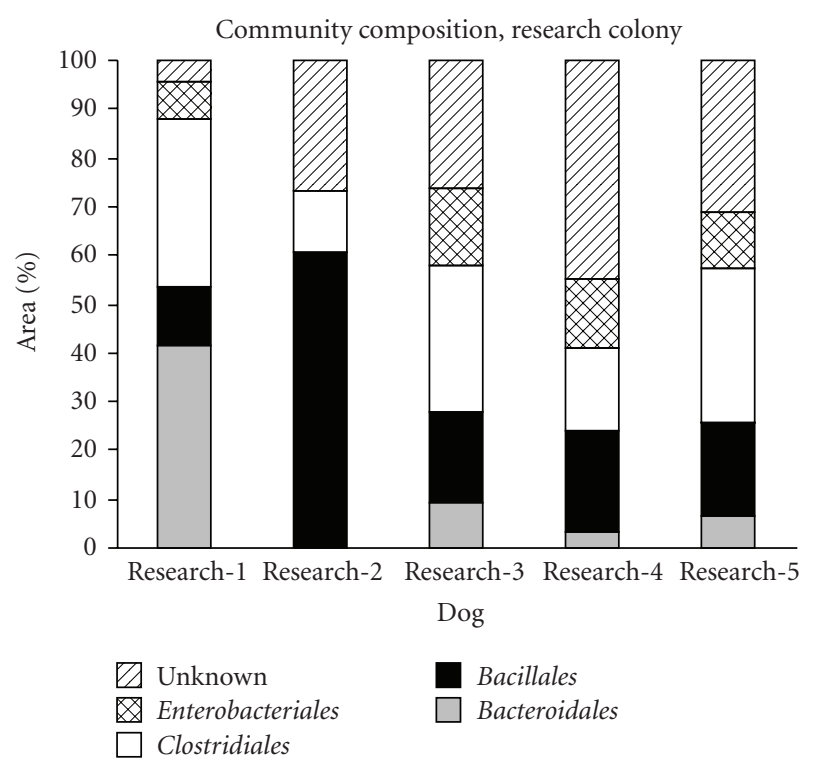

(a)

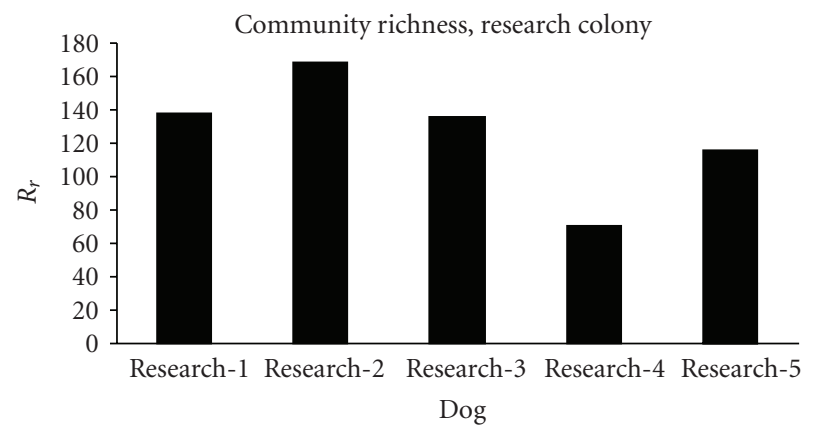

(c)

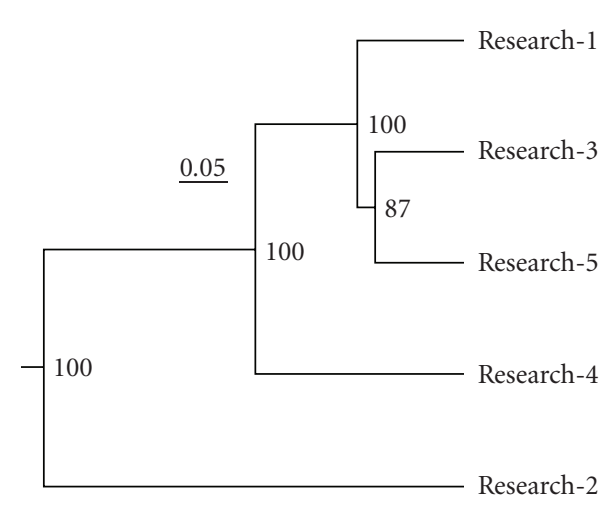

(b)

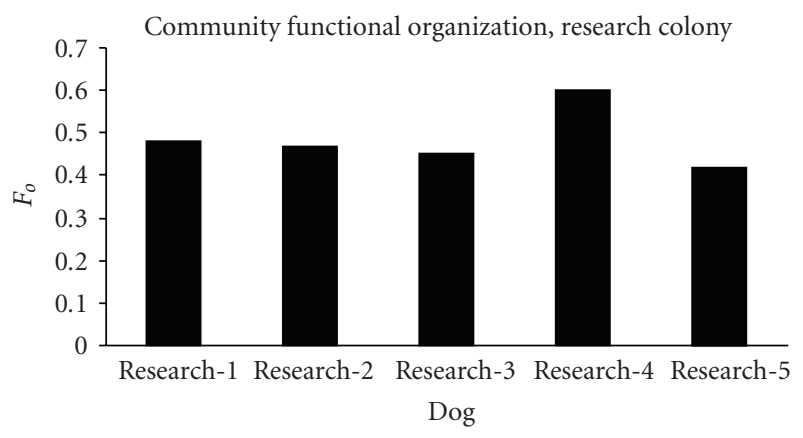

(d)

FIGURE 2: T-RFLP analysis of fecal samples from research colony dogs. Panel (a) community composition expressed as \% area of peaks under the T-RFLP electropherogram; bacterial groups were combined at the taxonomic level of order. Panel (b) dendrogram based on Bray-Curtis similarities of community composition among the five dogs; numbers at nodes indicate percentage of trees having an equivalent node in jackknife analysis. Panel (c) community richness parameter, $R r$. Panel (d) community functional organization, Fo.

environment. In addition, two of the four dogs living in households experienced diarrhea, one of them twice, after collection of the normal samples. We, therefore, collected samples from these dogs during and after treatment, if any, with the prescribed antibiotic.

Fecal samples were screened for Giardia by ELISA. One of two dogs (Pet 8 in Table 1) presenting to the MSU Small Animal Clinic with diarrhea was positive for Giardia; all others were negative. Fecal samples were screened for other parasites by fecal flotation; all were negative. DNA was extracted from each fecal sample and characterized using PCR for seven known enteric pathogens. Two of the five research colony dogs carried Enterococcus faecium, Campylobacter spp., and Helicobacter spp. (Research dogs 1 and 5). Two others of the five carried Enterococcus spp. and, Helicobacter spp. (Research dogs 2 and 4). The fifth research colony dog carried only Enterococcus faecium (Research $\operatorname{dog} 3$ ). Diagnostic PCR assays performed on fecal DNA obtained from the seven Giardia-negative household pets showed that five (Pets 1, 2, 3, 4, and 5) had at least one sample positive for Enterococcus spp., Helicobacter spp., and Campylobacter spp. during the sampling period; all three organisms were detected simultaneously in many samples. Pet 6 was positive for Campylobacter spp. and Enterococcus spp. but not Helicobacter spp. Pet 7, which presented to the MSU Small Animal Clinic with diarrhea, was positive for both Enterococcus spp. and Helicobacter spp. All thirteen dogs were negative for Salmonella spp. and Brachyspira spp.

\subsection{Bacterial communities in research colony dogs}

Results of T-RFLP analysis of fecal samples from research colony dogs are shown in Figure 2. Community composition is shown in Panel (a); for this figure, \% areas of peaks corresponding to the bacterial groups assigned by Nagashima et al. [31] were combined at the taxonomic level of order 
as follows: Bifidobacteriales (peak BslI 124), Bacillales (peaks BslI 322, 520, and 657), Bacteroidales (peaks BslI 317, 469, and 853), Clostridiales (peaks BslI 370, 494, 749, 919, and 955), Enterobacteriales (peak BslI 940), and Unknown (all peaks not classified in one of the previous groups). While a number of the BslI peaks defined by Nagashima et al. [31] contain organisms from more than one order, inspection of Table 1 in their publication shows that members of a single genus do dominate almost all peaks. The taxonomic level of order also captures some aspects of the physiology of intestinal bacteria that may be important in determining colonic health.

The fecal bacterial community composition of the genetically related research colony dogs was similar in four of five dogs (Figure 2, panels (a) and (b)). Dogs 1, 3, and 5 are housed in the same room and are the three research animals that were PCR-positive for Enterococcus faecium. The values of the community richness measure $R r$ for these communities are shown in Figure 2, Panel (c). These values were calculated using all peaks in each profile, not the combined order level data shown in Panel (a); values were comparable to those reported by Marzorati et al. [57] for microbially rich environments such as soils and sediments. Values of the community functional organization parameter (Fo reflects the "evenness" of the pattern of the relative abundances of the organisms) are shown in Figure 2, Panel (d); values ranged from 0.42 to 0.60 . Marzorati et al. [57] have characterized $R r$ values $>30$ as indicating environments capable of sustaining large, diverse communities. Fo values for the research colony dog fecal communities fall around 0.45 , a value which Marzorati et al. [57] have characterized as indicating a balanced community able to continue functioning properly during perturbations.

\subsection{Household pet dogs}

Results of T-RFLP analysis of fecal communities from two pet dogs (Pets 1 and 2) living in the same household and followed over time are shown in Figure 3. These dogs were genetically different and were fed different dry diets: an adult diet and a puppy diet from the same manufacturer. The adult dog (Pet 1) was allowed to roam freely in a rural environment, while the puppy (Pet 2) was exercised outdoors under the owners' supervision. The episode of diarrhea in Pet 1 on day 1 was due to dietary indiscretion and resolved by the next day; it was characterized by a "bloom" of BslI 940 (E. coli). Community compositions of fecal samples from the two dogs were dissimilar and exhibited considerable variation over time (Figure 3, Panel (a)). Nevertheless, five of six community composition patterns for Pet 2 did cluster together in the dendrogram shown in Figure 3, Panel (b). Values of the richness parameter $R r$ for Pet 1 ranged from 25 to 50; values of $R r$ for Pet 2 ranged from 11 to 147 (Figure 3, Panel (c)). These $R r$ values were generally lower than those obtained for the research colony dogs. Fo values ranged from 0.30 to 0.77 for Pet 1 and from 0.39 to 0.53 for Pet 2 (Figure 3, Panel (d)). Fo values for both dogs were more constant than either community composition or $R r$ values. The community dynamics \% change parameter was calculated for sequential samples (Figure 3, Panel (e)); because the time intervals between samples were not equal, we did not calculate the rate of change parameter $\Delta_{t}$. Values for Pet 1 ranged from 0.40 to 0.75 and for Pet 2 from 0.45 to 0.86 . These $\%$ change values are much higher than those reported for other kinds of microbial communities by Marzorati et al. [57].

One T-RFLP profile was obtained from another household pet (Pet 4); this animal was fed a commercial adult diet and occasional table scraps and allowed to roam freely in a suburban environment; both $R r$ and Fo values were low: 6.0 and 0.31 , respectively.

\subsection{Household pet dog with repeated diarrhea}

Results of T-RFLP analysis of fecal samples from a household pet dog (Pet 3) experiencing two separate episodes of diarrhea are shown in Figure 4. This animal was fed a commercial weight control dry diet two to four times higher in fiber than the diets of the other dogs in the study, and was consistently supervised by the owner when outdoors in a suburban environment. At the time of enrollment in the study, this pet was being treated for osteoarthritis with carprofen at $1.0 \mathrm{mg} / \mathrm{kg}$ BID; on day 121 after enrollment, the dosage was increased to $2.0 \mathrm{mg} / \mathrm{kg}$ BID. Moderate anorexia developed on day 151, and the owner began supplementing the diet in various ways to stimulate appetite; this supplementation continued throughout the rest of the study. After the second episode of diarrhea on day 168 , treatment with carprofen was discontinued and treatment with tramadol $(2.7 \mathrm{mg} / \mathrm{kg}$ TID) was instituted. Tramadol was discontinued due to vomiting on day 219 and deracoxib ( $1.4 \mathrm{mg} / \mathrm{kg}$ SID) was initiated; this drug was also not well tolerated and was discontinued on day 233. No further analgesics were given during the study.

Results of pathogen-specific PCR assays for this animal are shown in Table 3. Campylobacter and Helicobacter spp. were detected by PCR assay in 11 of 15 samples; the Campylobacter spp. PCR assay was positive in two samples taken on the day of onset of the first episode of diarrhea. Enterococcus faecalis and E. faecium assays were positive following the onset of the first episode of diarrhea. E. faecalis was not detected subsequently by this assay, while E. faecium levels were below the limit of detection until the onset of the second episode of diarrhea when the dog became positive over a course of 30 days.

Community composition was similar in the normal samples taken on days 1, 17, 70, 78, 85, 113, and 134 . Episodes of diarrhea occurred beginning on days 61 and 168; both episodes were treated with metronidazole (1st treatment starting on day $65(14.0 \mathrm{mg} / \mathrm{kg} \mathrm{BID}$, for 10 days $)$ and 2 nd treatment starting on day $172(14.0 \mathrm{mg} / \mathrm{kg}$ BID for 6 days)), and a brief period on a low-residue diet. Because the second episode of diarrhea occurred 107 days after the first and the microbiota returned to its starting composition during the interval, the second episode was probably not an antibiotic-associated diarrhea. Community composition returned to its starting composition after the first episode of diarrhea but not after the second; the two episodes were also different in character, the first being dominated by Enterobacteriales and Clostridiales and the 

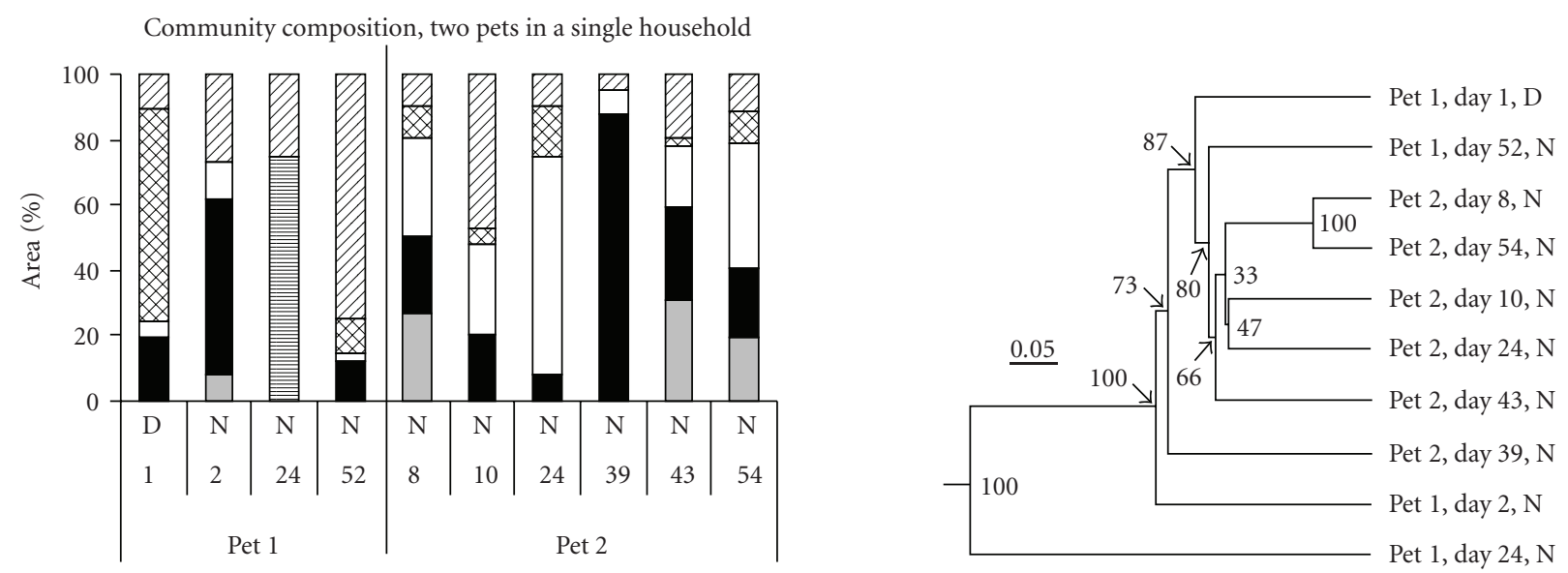

Dog, day of sampling, GI tract status

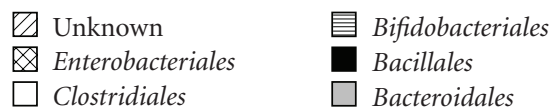

(a)

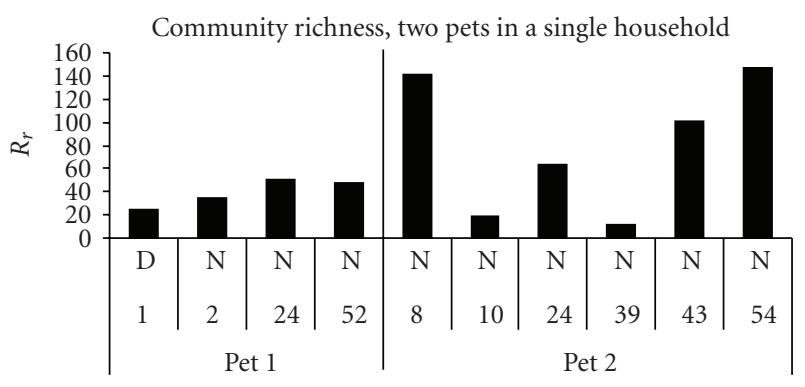

Dog, day of sampling, GI tract status

(c)

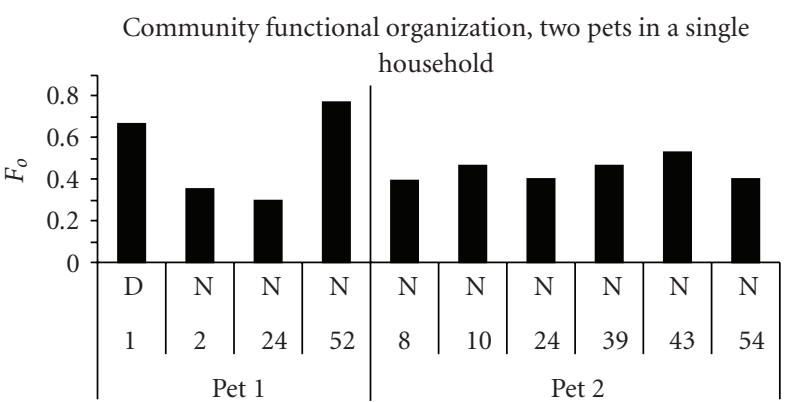

Dog, day of sampling, GI tract status

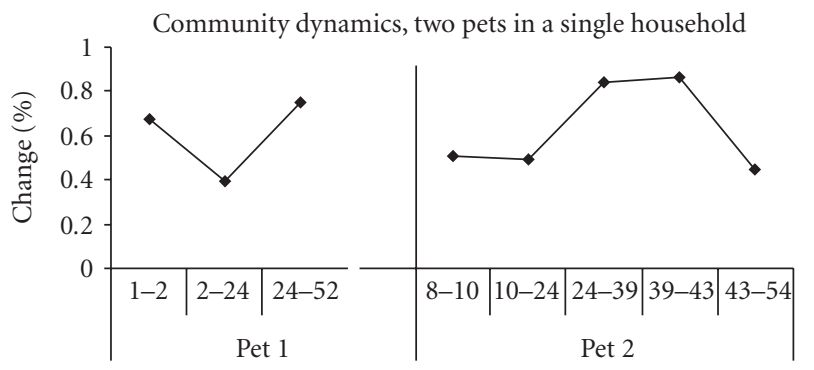

Dog, time interval (days)

(e)

FIGURE 3: T-RFLP analysis of fecal samples from two pets in a single household. Panel (a) community composition expressed as \% area of peaks under the T-RFLP electropherogram; bacterial groups were combined at the taxonomic level of order. Panel (b) dendrogram based on Bray-Curtis similarities of community composition among the samples from the two dogs; numbers at nodes indicate percentage of trees having an equivalent node in jackknife analysis. Panel (c) community richness parameter, $R r$. Panel (d) community functional organization, Fo. Panel (e) \% change parameter for community dynamics.

second by Bacillales. Simple fecal cytology performed by MSU VTH staff at the onset of the second episode of diarrhea was read out as bacterial overgrowth. The community did not begin to return to its previous composition for an extended period after the second episode of diarrhea. On the last day of sampling, representatives of all the orders previously present were detected, but their proportions were altered from those in the normal samples. The dendrogram 


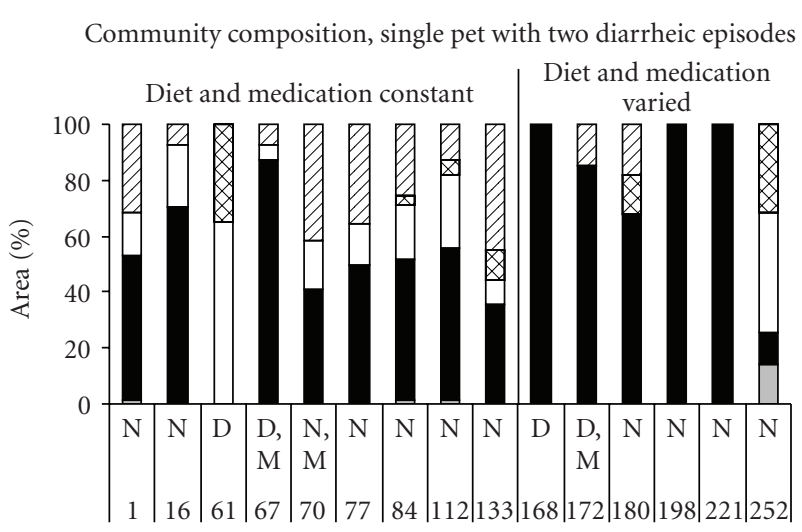

Day of sampling, GI tract status
$\triangle$ Unknown
Enterobacteriales
$\square$ Clostridiales

(a)

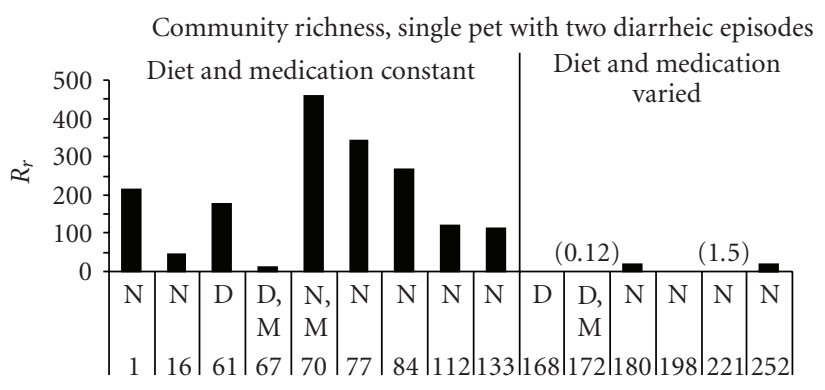

Day of sampling, GI tract status

(c)

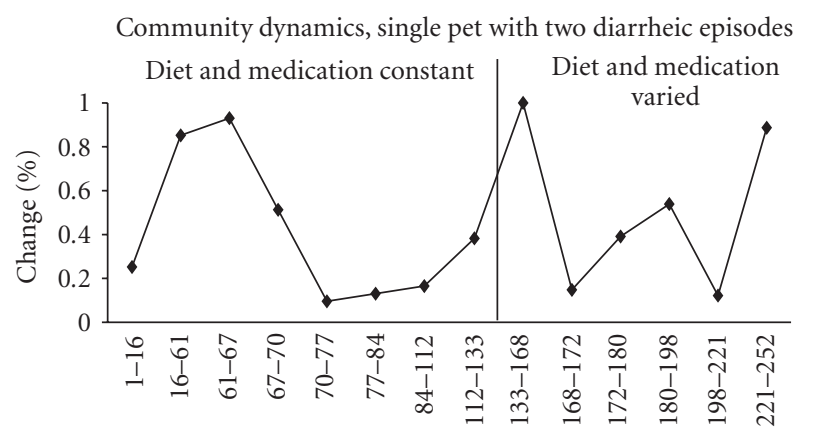

Time interval

(e)

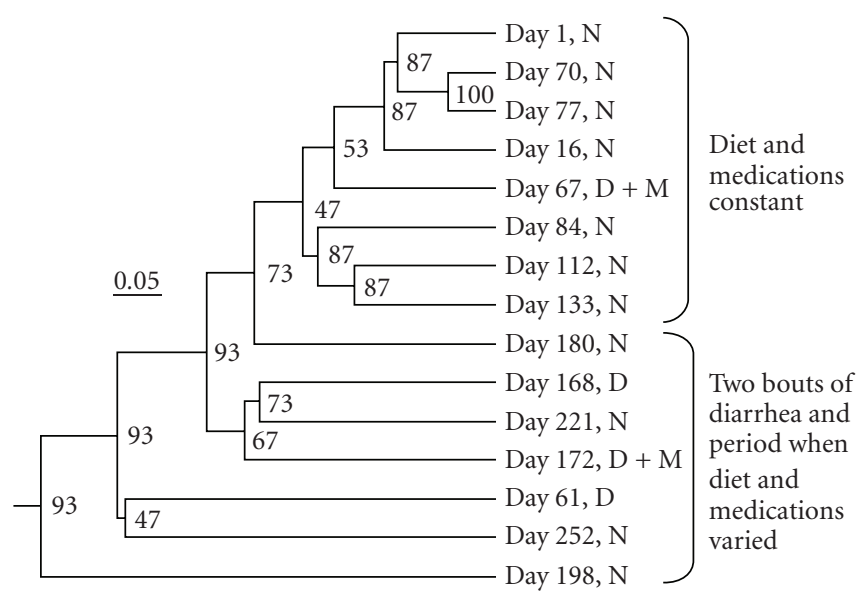

(b)

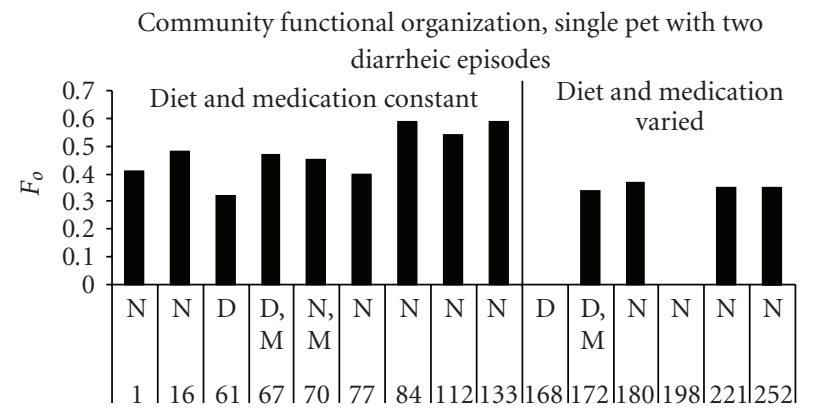

Day of sampling, GI tract status

(d)

Time lag analysis

diet and medications constant

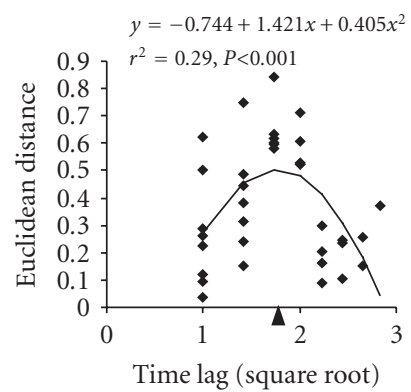

Time lag analysis diet and medications varied

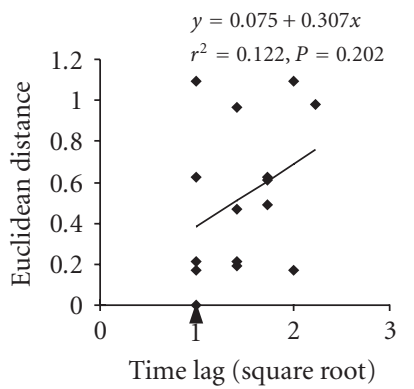

(f)

FIGURE 4: T-RFLP analysis of fecal samples from a single pet with two diarrheic episodes. Panel (a) community composition expressed as \% area of peaks under the T-RFLP electropherogram; bacterial groups were combined at the taxonomic level of order. Panel (b) dendrogram based on Bray-Curtis similarities of community composition among the samples from this dog; numbers at nodes indicate percentage of trees having an equivalent node in jackknife analysis. Panel (c) community richness parameter, $R r$. However, $R r$ is not reported when there was only a single peak $\geq 1 \%$ of the area under the electropherogram (days 168 and 198); the value of $R r$ was 0.12 on day 172 and 1.5 on day 221. Panel (d) community functional organization, Fo. However, Fo is not reported when there was only a single peak $\geq 1 \%$ of the area under the electropherogram (days 168 and 198). Panel (e) \% change parameter for community dynamics. Panel (f) time lag analysis. Arrows below the $X$-axis indicate the day of onset of an episode of diarrhea. 
TABLE 3: Detection of potential pathogens in pet dog with two diarrheic episodes by standard PCR assay*.

\begin{tabular}{|c|c|c|c|c|c|c|}
\hline Day & Status** & $\begin{array}{c}\text { Enterococcus } \\
\text { faecalis }\end{array}$ & $\begin{array}{c}\text { Enterococcus } \\
\text { faecium }\end{array}$ & $\begin{array}{l}\text { Campylobacter } \\
\text { spp. }\end{array}$ & $\begin{array}{c}\text { Helicobacter } \\
\text { spp. }\end{array}$ & $\begin{array}{l}\text { Clostridium } \\
\text { perfringens }\end{array}$ \\
\hline 1 & $\mathrm{~N}$ & - & - & + & + & - \\
\hline 16 & $\mathrm{~N}$ & - & - & - & + & - \\
\hline 61 & $\mathrm{D}$ & - & - & + & + & + \\
\hline 67 & $\mathrm{D}, \mathrm{M}$ & + & + & - & - & + \\
\hline 70 & $\mathrm{~N}, \mathrm{M}$ & + & + & - & - & - \\
\hline 77 & $\mathrm{~N}$ & - & - & - & - & + \\
\hline 84 & $\mathrm{~N}$ & - & - & - & + & + \\
\hline 112 & $\mathrm{~N}$ & - & \pm & - & + & - \\
\hline 133 & $\mathrm{~N}$ & - & - & - & + & - \\
\hline 168 & $\mathrm{D}$ & - & + & - & - & + \\
\hline 172 & $\mathrm{D}, \mathrm{M}$ & - & + & - & + & + \\
\hline 180 & $\mathrm{~N}$ & - & + & - & + & + \\
\hline 198 & $\mathrm{~N}$ & - & \pm & - & + & + \\
\hline 221 & $\mathrm{~N}$ & - & - & - & + & + \\
\hline 252 & $\mathrm{~N}$ & - & - & - & + & + \\
\hline
\end{tabular}

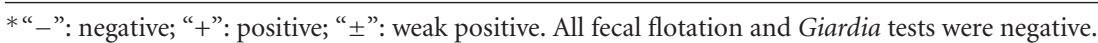

**N: normal; D: diarrhea: M: metronidazole treatment.

showing the similarities of the communities at different times (Figure 4, Panel (b)) also demonstrates this pattern: most of the samples taken prior to day 168 cluster together and away from the diarrheic samples and the normal samples taken after the second episode of diarrhea.

Changes in community richness parameter $R r$ values are shown in Figure 4, Panel (c). Community richness dropped to a value of 11.2 following institution of metronidazole treatment for the first episode of diarrhea but rebounded to a high level (460) and then declined slowly over the next month. Richness was severely reduced during the second episode of diarrhea and did not return to even moderate levels; repeated changes in medications and diet were made during the period after the second episode of diarrhea. Changes in Fo values (Figure 4, Panel (d)) were less pronounced but consistently somewhat lower after the second episode of diarrhea.

Changes in the community dynamics parameter \% change also reflect the events described above (Figure 4, Panel (e)). Large values (0.85 to 0.99$)$ are associated with the two episodes of diarrhea. Prior to the first episode of diarrhea and after recovery from it, the \% change values ranged from 0.09 to 0.38 and were comparable to those reported for other kinds of communities by Marzorati et al. [57]. Marzorati et al. characterized \% change values around 0.10 as indicating that the community is stable; new organisms are able to become established but do not interfere with community function. Very high \% change values were associated with the diarrheic episodes in Pet 3, and after the second episode, the $\%$ change values continued to fluctuate, indicating that the community did not return to stability. This period of instability coincided with the period of repeated changes in medications and diet.

Temporal variability in the T-RFLP data was also analyzed using the regression method of Collins et al. [58]
(Figure 4, panel (f)); the period when diet and medication were constant and the period when both varied were analyzed separately. The period when diet and medications were constant, which included the first episode of diarrhea, exhibited a phase with a positive slope followed by a phase with a negative slope. This pattern can be interpreted as showing a directional change in community composition after a perturbation followed by a return to the starting condition [58]. The period when diet and medications were varied did not yield a significant regression; according to Collins et al. [58], this result indicates fluctuating changes in community composition over time.

\subsection{Q-PCR analysis of fecal samples from a household pet dog experiencing repeated episodes of diarrhea}

To explore further the results for Pet 3 obtained from TRFLP analysis, we performed quantitative real-time PCR on the same DNA samples used for T-RFLP. Q-PCR results are shown in Figure 5, Panels (a) to (f). Population variability (PV) values were high (range: $0.768-0.915$ ) for all organisms assayed. Clostridium groups I and XIVa were analyzed separately; group I contains the potential enteric pathogen C. perfringens. (C. difficile is a member of Clostridium group $\mathrm{XI}$ and would not be detected by these assays.) Both groups were detected by Q-PCR throughout the sampling period. Clostridium group I levels were relatively constant, except for an 880-fold increase coincident with the first episode of diarrhea (day 61); the Clostridiales peaks comprised 55\% of the total area under the electropherogram for that sample in the T-RFLP analysis (Figure 4(a)), and the BslI 749 peak comprised $40 \%$ of the total area under the electropherogram (data not shown). The BslI 749 peak is included in the Clostridiales portion of the bar in Figure 4(a). The expected 


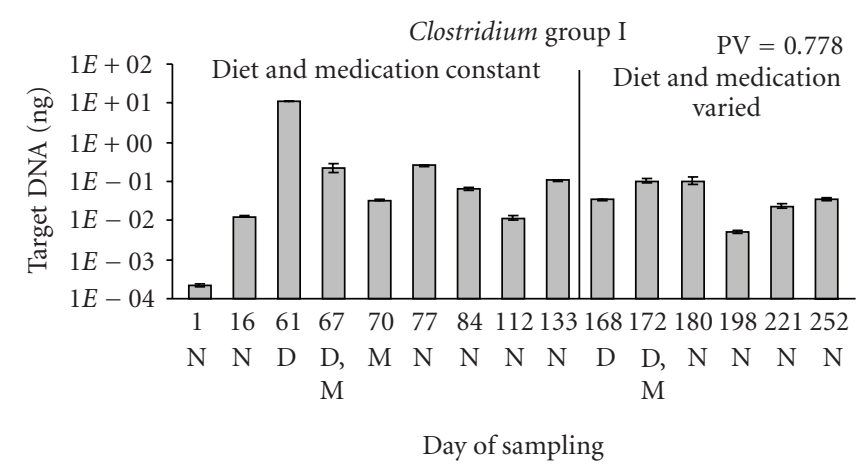

(a)

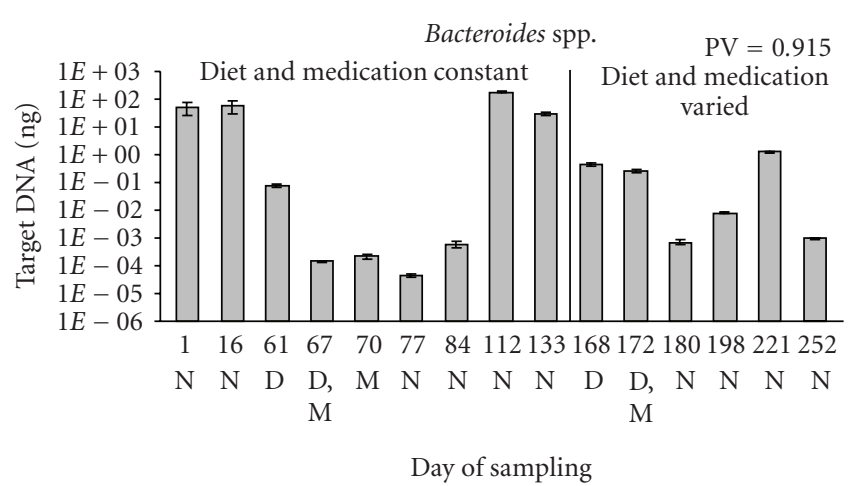

(c)

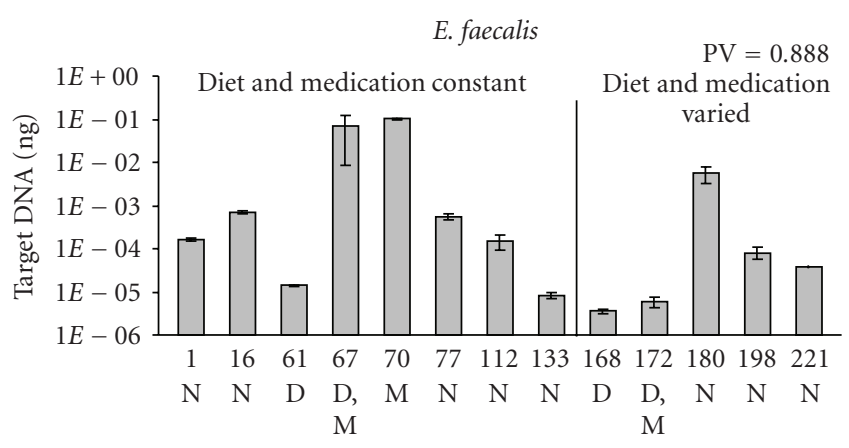

Day of sampling

(e)

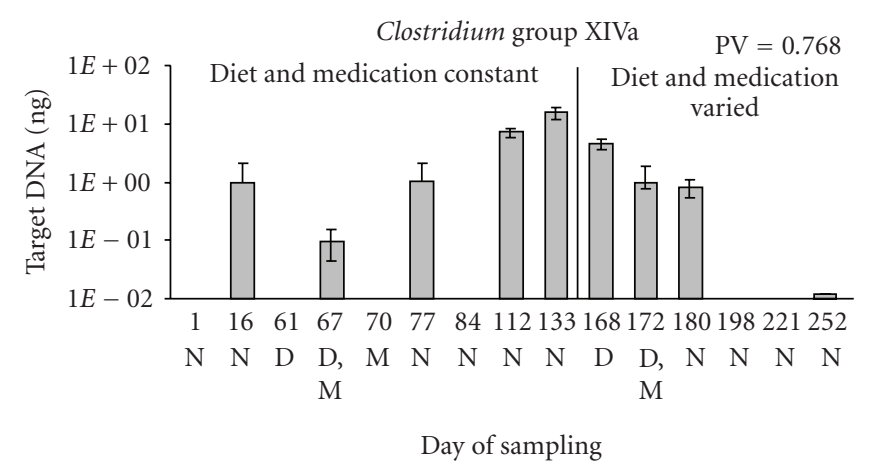

(b)

$$
\text { E. faecium }
$$

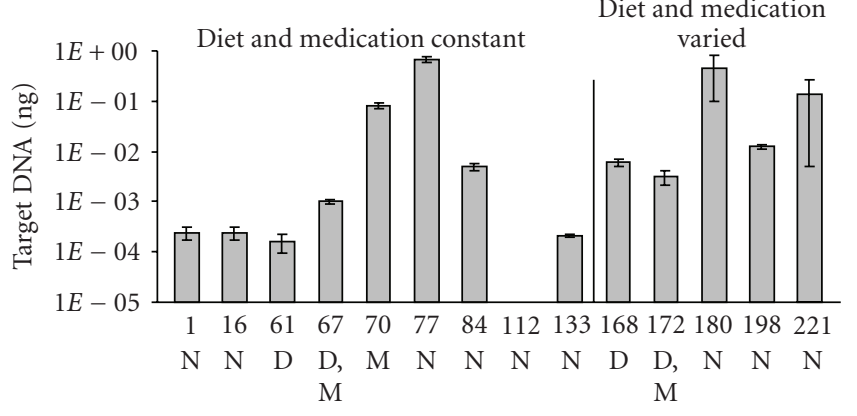

Day of sampling

(d)

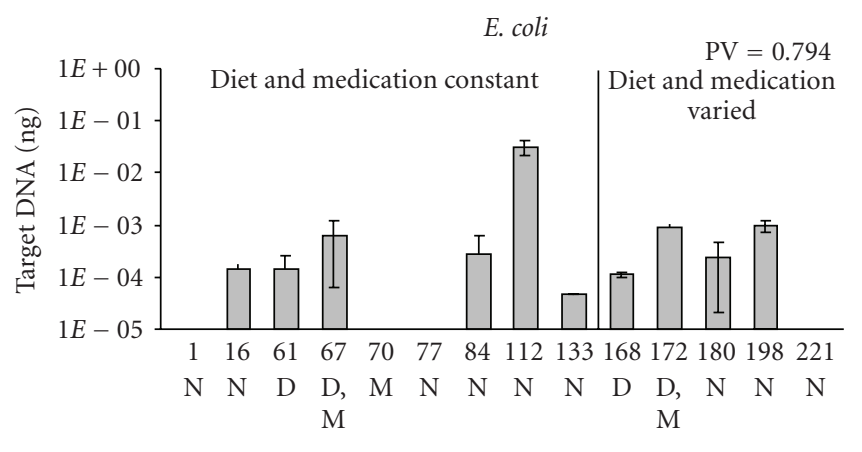

Day of sampling

(f)

FIGURE 5: Q-PCR analysis of bacterial groups in fecal samples from a single pet with two diarrheic episodes. Panel (a) Clostridium group I; Panel (b) Clostridium group XIVa; Panel (c) Bacteroides spp.; Panel (d) E. coli; Panel (e) E. faecium; Panel (f) E. faecalis. $R^{2}$ values for the standard curves were $0.995,0.986,0.956,0.958,0.980$, and 0.998, respectively. Error bars indicate the standard deviation of triplicate samples. Lack of a bar indicates that no product was detected in 40 cycles. The sample for day 252 was exhausted before Q-PCR for E. faecium, E. faecalis, and E. coli was performed. Population variability (PV) values are shown at the upper right of each panel.

BslI peak size for Clostridium perfringens is approximately $750 \mathrm{bp}$. Once this result was obtained, we performed a specific PCR assay for Clostridium perfringens [45]. That assay was negative prior to the first episode of diarrhea, it became strongly positive in the first diarrheic sample (Table 3), and remained so in all but one sample for about three weeks. Four weeks after the last positive sample, the assay was negative and remained so until the onset of the second episode of diarrhea, when it became strongly positive again. It remained positive throughout the second metronidazole treatment and was still positive twelve weeks later.

Clostridium group XIVa levels were more variable and did not exhibit any pattern with respect to either episode of diarrhea. Levels of E. coli exhibited a peak on day 112 but also did not exhibit any pattern with respect to either episode of diarrhea.

Levels of E. faecium and E. faecalis both rose after the initiation of metronidazole treatment during both episodes 
of diarrhea. E. faecium rose 4000-fold between the onset of the first episode of diarrhea (day 61) and day 77 and 77-fold between the onset of the second episode of diarrhea (day 168) and day 180. E. faecalis rose 7000-fold between the onset of the first episode of diarrhea (day 61) and day 70 and 1500fold between the onset of the second episode of diarrhea (day 168) and day 180.

Q-PCR assay detected Bacteroides in all samples. Levels of Bacteroides spp. were highest in normal samples taken during the period when diet and medications were constant. Bacteroides spp. decreased approximately $10^{5}$-fold during and following the first episode of diarrhea but returned to the original levels. Levels decreased approximately $10^{4}-$ fold during the second episode of diarrhea and fluctuated thereafter. This result is in marked contrast to the T-RFLP assay, which seldom detected Bacteroides at levels exceeding $1 \%$ of the total area under the electropherogram.

\section{DISCUSSION}

Screening for specific pathogens by PCR revealed that most animals carried one or more potential enteric pathogens in their fecal microbiota even when they had no clinical signs. Thus, many cases of "spontaneous" diarrhea in dogsand by extension, sporadic diarrhea in humans-may be caused by organisms already present in the GI tract following perturbation of the microbiota by an environmental factor rather than by a pathogen acquired from another source $[6,61]$. The hypothesis that alterations in the microbiota may inhibit or facilitate disease processes has been invoked in the context of chronic inflammatory bowel diseases; our results support the idea that there may be a significant role for the microbiota in acute infectious disease processes. Other clinical and experimental studies suggest that the relative balance of aggressive and protective bacterial species is altered in inflammatory diseases such as Crohn's disease (CD), ulcerative colitis (UC), and pouchitis. In a review of current work in this area, it was postulated that overly aggressive immune responses to a subset of commensal (nonpathogenic) enteric bacteria in genetically predisposed individuals result in disease [62]. Recently, Frank et al. showed that CD patients, UC patients, and noninflamed controls had statistically significantly different microbiotas based on culture-independent rRNA sequence analysis of cloned libraries [63]. Because it was based on surgical samples of colon, this study provided a survey of gutwall associated microbiota relevant to Inflammatory Bowel Disease. Here, as in all studies using methods based on SSU rRNA, bacterial "numbers" were recognized to be relative estimates reflecting gene copy numbers and not indicative of causation. However, microbiota surveys can provide candidates for hypothesis testing of causation. In our study, fecal samples could be argued to best represent "diagnostic" samples that would be taken from a host presenting with acute diarrhea. It is acknowledged that further work will be needed to document the ability of readily available fecal samples to represent different locations within the colon to document the etiologies of these diarrheas [64].
The influence of diet and medication on the intestinal microbiota has been studied directly in animals and humans $[17,18,21,29,62]$. Although it was not our intent to study such effects, our results confirm that the composition of the intestinal microbiota is quite sensitive to changes in environmental factors such as changes in diet and/or medications as well as exposure to the microbiotas of other animals. The relatively consistent microbiotas of the research colony dogs are in marked contrast to the fluctuations observed in Pet 1, which roamed freely in a rural environment. The microbiotas of Pets 2 and 3, which were more closely supervised when out of doors, showed less variability than that observed in Pet 1 but more than in the research colony dogs. Finally, fluctuations in the microbiota of Pet 3 became much more pronounced when diet and medication were changed.

Comparison of results from T-RFLP and Q-PCR results for Pet 3 showed that both methods can detect variation in the microbiota associated with events such as diarrheal episodes and changes in diet and medication. The extensive variability in the abundances of the different groups of organisms evident in the T-RFLP data was also evident in the Q-PCR results for individual groups and organisms; population variability (PV) values for all organisms assayed by Q-PCR were high. This result is not surprising given the wide range of target DNA concentrations detected by this assay (lowest detected level, $3.6 \times 10^{-6} \mathrm{ng}$ for E. faecalis; highest detected level, $1.8 \times 10^{2} \mathrm{ng}$ for Bacteroides).

The T-RFLP analysis indicated that there was a large increase in Clostridiales, including the BslI $749 \mathrm{bp}$ peak defined by Nagashima et al. [31], on day 61, the day of onset of the first episode of diarrhea. Q-PCR analysis indicated an increase in Clostridium group I, of which C. perfringens is a member, which coincided with the onset of the first episode of diarrhea. Diagnostic PCR assays for C. perfringens showed that this organism was temporally associated with the onset of both episodes of diarrhea. But because the time intervals that elapsed between samples were long, we cannot determine whether the increases in Clostridium group I or the detection of $C$. perfringens reflected causes or consequences of the episodes of diarrhea. The data thus suggest but do not prove that the illness was caused by a member of Clostridium group I, possibly C. perfringens. However, C. perfringens remained at detectable levels during the period when diet and medications varied. This result suggests that the instability of the microbial community during this period facilitated the growth of this potential pathogen.

T-RFLP analysis also indicated large increases in Bacillales; which includes lactobacilli, streptococci, and enterococci; subsequent to metronidazole treatment. In Q-PCR analysis, both E. faecium and E. faecalis exhibited repeated substantial increases after the initiation of metronidazole treatment, and after the second episode of diarrhea, $E$. faecium levels did not return to those seen at the beginning of the study. These results suggest that, in view of the potential of both E. faecium and E. faecalis to have deleterious effects on the GI tract, the use of metronidazole as a first-line treatment for canine diarrhea should be re-evaluated. 
Perturbations in Bacteroides spp. levels associated with the two episodes of diarrhea were also apparent; levels of these organisms decreased during both episodes of diarrhea and became unstable during the period when diet and medication were varied. Since Bacteroides spp. are major components of the colon microbial community and essential to its function, such fluctuations might be expected to have repercussions for colon health.

The discrepancy between the two methods in detecting the genus Bacteroides in this animal would be most simply explained as a relative inability of the universal eubacterial $16 \mathrm{~S}$ primers used to bind to the $16 \mathrm{~S}$ rDNA sequences of the particular Bacteroides spp. predominating in that dog compared to the more specific primers used in the QPCR assay. However, members of the Bacteroidales were detected by the primers used in T-RFLP analysis in four of the five research colony dogs and in Pets 1 and 2. BLAST searches indicated that the region of homology between the Nagashima et al. [31] reverse primer to the 16S rDNA sequence of (1) some but not all strains of Bacteroides eggerthii, (2) some but not all strains of B. stercoris, and (3) some but not all strains of $B$. caccae consists only of the seven bases from nucleotide 11 to nucleotide 17 of the 19-base primer. This limited homology was even present in the $16 \mathrm{~S}$ rDNA sequences of the type strains of $B$. stercoris and B. caccae. No PCR product would be obtained from DNA of these strains. Also, BLAST searches indicated that the 16S primers used for the Q-PCR studies [51] would be expected to amplify rDNA of all strains of these three species. However, B. eggerthii, B. stercoris, and B. caccae are found in humans; in a cloned library study, sequences closely related to $B$. stercoris were obtained from dogs [20]. Of the Bacteroides spp. sequences obtained from dogs in the latter study, one was very similar to that of B. stercoris, three were similar to that of B. vulgatus, and four were not similar to those of any of the published Bacteroides spp. used in the analysis. The same study also indicated that the Bacteroides spp. sequences from the fecal microbial communities of humans, dogs, cats, and gulls clustered together and separately from those of cattle and elk.

We applied the community characterization schema proposed by Marzorati et al. [57] to the dog fecal bacterial communities studied here and related them to what we know about the management and clinical presentation of the dogs. The research colony dog communities were characterized by high richness and intermediate "balanced" levels of functional organization. Because of the constancy of the environment of these dogs, we predict that their communities would experience low-to-medium dynamics similar to those observed in normal samples from Pet 3 . The communities of Pets 1, 2, and 4 were generally characterized by lower richness, balanced functional organization, and high levels of dynamic change for Pets 1 and 2.

The normal communities of Pet 3 prior to and following the first episode of diarrhea were characterized by high richness, medium levels of dynamic change, and balanced functional organization, while the diarrheic samples were characterized by low richness, high levels of dynamic change, and low levels of functional organization. Communities in the normal samples taken following the second episode of diarrhea were characterized by continued low richness, fluctuating levels of dynamic change, and somewhat lower levels of functional organization than previous normal samples. The fluctuating levels of dynamic change were temporally correlated with changes in diet and medication. Time lag analysis indicated that samples taken when diet and medication were constant-the initial samples, samples taken during the first episode of diarrhea, and samples taken prior to the second episode of diarrhea-showed a recognizable pattern of disturbance followed by a return to the initial condition. Samples taken when diet and medications were varied-beginning with the onset of the second episode diarrhea and continuing to the end of the study-did not exhibit any directional changes but instead showed random fluctuation. The general agreement between these complementary analyses suggests that concepts from macroecology will be useful in interpreting data from microbial communities.

According to Marzorati et al. [57], the level of the community richness parameter $R r$ is indicative of the carrying capacity of the environment; diet is one obvious environmental variable that might affect the carrying capacity in the GI tract. The similar values of $R r$ obtained for research colony dogs fed and housed under controlled conditions supports this idea. However, Pet 2 was genetically related to the research colony dogs and was fed a similar diet, but exhibited lower community richness. This free-roaming dog probably had a much more variable intake than the research colony dogs, so values for apparent carrying capacity might have been influenced by the highly dynamic nature of the microbial community in this animal. A similar effect can be seen in the richness parameter values for Pet 3; $R r$ varied widely subsequent to perturbation and periods of dynamic change in the community due to episodes of diarrhea.

The level of dynamic change also varied considerably in Pets 1, 2, and 4, and was correlated with environmental factors in that Pets 1 and 2 experienced both more environmental variation and consistently higher levels of change in community composition than did Pet 3 during healthy periods. The community functional organization parameter Fo is held by Marzorati et al. [57] to reflect the resistance of the community structure to perturbation. If Fo values do predict community resiliency, then such resiliency may explain why both Pet 1 and Pet 2, which had relatively robust Fo values, were mainly non-diarrheic in spite of having high levels of dynamic change and substantially shifting community compositions. In the case of Pet 1 , the latter phenomena may have been due to varied intake of substances from the environment; in the case of Pet 2, a puppy, these phenomena may have been due to maturation processes in the GI tract. In addition, after the second episode of diarrhea in Pet 3, Fo values declined and the community appeared to become less stable under the influence of changing diet and medication regimes; this observation further supports the connection between functional organization and resiliency.

Studies with larger sample sizes are required to substantiate these apparent correlations in a rigorous way. Also, more work is clearly needed to delineate the variability of 
the microbiota of the healthy GI tract before embarking on detailed studies of disease states. However, based on these observations, we would predict that if the normal or background variability is substantial, it may prove exceedingly difficult to detect relevant changes in heterogeneous populations such as individuals enrolled in clinical trials.

\section{CONCLUSIONS}

We hypothesized that dogs have a stable composition of the colon microbial community and that episodes of diarrhea lead to long lasting changes in community composition and/or function; furthermore, treatment for specific pathogens can compound these effects. Outbred monogastric animals like dogs can serve as easily manipulable models to address approaches for problems of the human GI tract. Thus, the microbiota of dogs was studied during diarrheic episodes and compared to those of healthy control dogs to make a preliminary assessment of the contribution of members of the microbiota to acute diarrheal disease processes. We found that (1) four of five dogs living in an environment expected to provide the least exposure to factors that might alter the GI tract microbiota had similar microbiotas, (2) the microbiotas of dogs kept in more variable environments were correspondingly more variable, (3) acute episodes of diarrhea resulted in large-scale changes in the GI tract microbiota, and (4) when the diet and medications of a dog having a previously stable microbiota were changed repeatedly, the GI tract microbiota also changed repeatedly, ultimately reducing richness. The high levels of variability we encountered in the pet dogs indicate that descriptive population-based microbiota studies may be so fraught with variation within and between individuals that meaningful patterns and changes may be hard to distinguish from the "noise." Either longitudinal studies of individuals under relatively constant environmental regimes (Pet 3) or model-based studies of groups of individuals under strictly controlled environments (research colony dogs) with planned experimental interventions could be expected to yield interpretable results. The consistency of the microbial communities in the research colony dogs and the changes we were able to observe in Pet 3 indicate that it is possible to establish baseline starting conditions and that the methods employed in these studies can be used to detect and delineate changes in fecal microbial communities. We expect these considerations derived from this useful animal model to apply with equal force to studies in humans.

\section{ACKNOWLEDGMENTS}

We thank the Companion Animal Fund of the MSU College of Veterinary Medicine for funding this project. We thank Sarah Apodaca, John Fyfe, Karl Hanover, two clients of the MSU VTH, and especially Sally Lloyd, for providing samples and information on dogs enrolled in the study. We thank Drs. Valerie Chadwick, Julie Schildt, and John Fyfe for their expertise in physical examination of dogs in these studies. We thank Drs. Mahdi Saeed, Thaddeus Stanton, and Vince
Young for gifts of genomic DNAs for use as positive controls for PCR assays.

\section{REFERENCES}

[1] N. M. Thielman and R. L. Guerrant, "Acute infectious diarrhea," The New England Journal of Medicine, vol. 350, no. 1, pp. 38-47, 2004.

[2] N. J. Asha and M. H. Wilcox, "Laboratory diagnosis of Clostridium perfringens antibiotic-associated diarrhoea," Journal of Medical Microbiology, vol. 51, no. 10, pp. 891-894, 2002.

[3] A. L. Struble, Y. J. Tang, P. H. Kass, P. H. Gumerlock, B. R. Madewell, and J. Silva Jr., "Fecal shedding of Clostridium difficile in dogs: a period prevalence survey in a veterinary medical teaching hospital," Journal of Veterinary Diagnostic Investigation, vol. 6, no. 3, pp. 342-347, 1994.

[4] A. A. Adesiyun, M. Campbell, and J. S. Kaminjolo, "Prevalence of bacterial enteropathogens in pet dogs in Trinidad," Zentralblatt für Veterinärmedizin B, vol. 44, no. 1, pp. 19-27, 1997.

[5] D. Linton, R. J. Owen, and J. Stanley, "Rapid identification by PCR of the genus Campylobacter and of five Campylobacter species enteropathogenic for man and animals," Research in Microbiology, vol. 147, no. 9, pp. 707-718, 1996.

[6] L. Beutin, "Escherichia coli as a pathogen in dogs and cats," Veterinary Research, vol. 30, no. 2-3, pp. 285-298, 1999.

[7] T. Furukawa, K. Furumoto, M. Fujieda, and E. Okada, "Detection by PCR of the Tyzzer's disease organism (Clostridium piliforme) in feces," Experimental Animals, vol. 51, no. 5, pp. 513-516, 2002.

[8] G. E. Duhamel, "Comparative pathology and pathogenesis of naturally acquired and experimentally induced colonic spirochetosis," Animal Health Research Reviews, vol. 2, no. 1, pp. 3-17, 2001.

[9] J. E. Collins, M. E. Bergeland, C. J. Lindeman, and J. R. Duimstra, "Enterococcus (Streptococcus) durans adherence in the small intestine of a diarrheic pup," Veterinary Pathology, vol. 25, no. 5, pp. 396-398, 1988.

[10] N. Misawa, K. Kawashima, F. Kondo, E. Kushima, K. Kushima, and P. Vandamme, "Isolation and characterization of Campylobacter, Helicobacter, and Anaerobiospirillum strains from a puppy with bloody diarrhea," Veterinary Microbiology, vol. 87, no. 4, pp. 353-364, 2002.

[11] G. Rossi, M. Rossi, C. G. Vitali, et al., "A conventional beagle dog model for acute and chronic infection with Helicobacter pylori," Infection and Immunity, vol. 67, no. 6, pp. 3112-3120, 1999.

[12] J. G. Fox, "The expanding genus of Helicobacter: pathogenic and zoonotic potential," Seminars in Gastrointestinal Disease, vol. 8, no. 3, pp. 124-141, 1997.

[13] M. Rinkinen, K. Jalava, E. Westermarck, S. Salminen, and A. C. Ouwehand, "Interaction between probiotic lactic acid bacteria and canine enteric pathogens: a risk factor for intestinal Enterococcus faecium colonization?" Veterinary Microbiology, vol. 92, no. 1-2, pp. 111-119, 2003.

[14] S. L. Marks, E. J. Kather, P. H. Kass, and A. C. Melli, "Genotypic and phenotypic characterization of Clostridium perfringens and Clostridium difficile in diarrheic and healthy dogs," Journal of Veterinary Internal Medicine, vol. 16, no. 5, pp. 533-540, 2002.

[15] W. Vahjen and K. Männer, "The effect of a probiotic Enterococcus faecium product in diets of healthy dogs on bacteriological counts of Salmonella spp., Campylobacter spp. and Clostridium 
spp. in faeces," Archiv für Tierernahrung, vol. 57, no. 3, pp. 229-233, 2003.

[16] D. Carre, T. Coton, R. Delpy, M. Guisset, and J. M. Debonne, "Acute infectious diarrhea: current treatment and perspectives," Medecine Tropicale, vol. 61, no. 6, pp. 521-528, 2001.

[17] H. L. Greetham, C. Giffard, R. A. Hutson, M. D. Collins, and G. R. Gibson, "Bacteriology of the Labrador dog gut: a cultural and genotypic approach," Journal of Applied Microbiology, vol. 93, no. 4, pp. 640-646, 2002.

[18] J. S. Suchodolski, J. Camacho, and J. M. Steiner, "Analysis of bacterial diversity in the canine duodenum, jejunum, ileum, and colon by comparative 16S rRNA gene analysis," FEMS Microbiology Ecology, vol. 66, no. 3, pp. 567-578, 2008.

[19] X. Wang, S. P. Heazlewood, D. O. Krause, and T. H. J. Florin, "Molecular characterization of the microbial species that colonize human ileal and colonic mucosa by using $16 \mathrm{~S}$ rDNA sequence analysis," Journal of Applied Microbiology, vol. 95, no. 3, pp. 508-520, 2003.

[20] L. K. Dick, A. E. Bernhard, T. J. Brodeur, et al., "Host distributions of uncultivated fecal Bacteroidales bacteria reveal genetic markers for fecal source identification," Applied and Environmental Microbiology, vol. 71, no. 6, pp. 3184-3191, 2005.

[21] K. S. Swanson, C. M. Grieshop, E. A. Flickinger, et al., "Fructooligosaccharides and Lactobacillus acidophilus modify gut microbial populations, total tract nutrient digestibilities and fecal protein catabolite concentrations in healthy adult dogs," Journal of Nutrition, vol. 132, no. 12, pp. 3721-3731, 2002.

[22] R. E. Ley, C. A. Lozupone, M. Hamady, R. Knight, and J. I. Gordon, "Worlds within worlds: evolution of the vertebrate gut microbiota," Nature Reviews Microbiology, vol. 6, no. 10, pp. 776-788, 2008.

[23] R. E. Ley, M. Hamady, C. Lozupone, et al., "Evolution of mammals and their gut microbes," Science, vol. 320, no. 5883, pp. 1647-1651, 2008.

[24] V. J. McCracken and R. G. Lorenz, "The gastrointestinal ecosystem: a precarious alliance among epithelium, immunity and microbiota," Cellular Microbiology, vol. 3, no. 1, pp. 1-11, 2001.

[25] W. E. C. Moore and L. V. Holdeman, "Human fecal flora: the normal flora of 20 Japanese-Hawaiians," Journal of Applied Microbiology, vol. 27, no. 5, pp. 961-979, 1974.

[26] P. B. Eckburg, E. M. Bik, C. N. Bernstein, et al., "Diversity of the human intestinal microbial flora," Science, vol. 308, no. 5728, pp. 1635-1638, 2005.

[27] E. Furrie, "A molecular revolution in the study of intestinal microflora," Gut, vol. 55, no. 2, pp. 141-143, 2006.

[28] R. D. Berg, "The indigenous gastrointestinal microflora," Trends in Microbiology, vol. 4, no. 11, pp. 430-435, 1996.

[29] J. M. Simpson, B. Martineau, W. E. Jones, J. M. Ballam, and R. I. Mackie, "Characterization of fecal bacterial populations in canines: effects of age, breed and dietary fiber," Microbial Ecology, vol. 44, no. 2, pp. 186-197, 2002.

[30] D. S. Nielsen, P. L. Møller, V. Rosenfeldt, A. Pærregaard, K. F. Michaelsen, and M. Jakobsen, "Case study of the distribution of mucosa-associated Bifidobacterium species, Lactobacillus species, and other lactic acid bacteria in the human colon," Applied and Environmental Microbiology, vol. 69, no. 12, pp. 7545-7548, 2003.

[31] K. Nagashima, T. Hisada, M. Sato, and J. Mochizuki, "Application of new primer-enzyme combinations to terminal restriction fragment length polymorphism profiling of bacterial populations in human feces," Applied and Environmental Microbiology, vol. 69, no. 2, pp. 1251-1262, 2003.

[32] M. F. Polz and C. M. Cavanaugh, "Bias in template-to-product ratios in multitemplate PCR," Applied and Environmental Microbiology, vol. 64, no. 10, pp. 3724-3730, 1998.

[33] A. Schmalenberger, F. Schwieger, and C. C. Tebbe, "Effect of primers hybridizing to different evolutionarily conserved regions of the small-subunit rRNA gene in PCR-based microbial community analyses and genetic profiling," Applied and Environmental Microbiology, vol. 67, no. 8, pp. 3557-3563, 2001.

[34] J. J. Engebretson and C. L. Moyer, "Fidelity of select restriction endonucleases in determining microbial diversity by terminalrestriction fragment length polymorphism," Applied and Environmental Microbiology, vol. 69, no. 8, pp. 4823-4829, 2003.

[35] Y. Hongoh, H. Yuzawa, M. Ohkuma, and T. Kudo, "Evaluation of primers and PCR conditions for the analysis of $16 \mathrm{~S}$ rRNA genes from a natural environment," FEMS Microbiology Letters, vol. 221, no. 2, pp. 299-304, 2003.

[36] J. S. Weese, H. R. Staempfli, and J. F. Prescott, "Survival of Clostridium difficile and its toxins in equine feces: implications for diagnostic test selection and interpretation," Journal of Veterinary Diagnostic Investigation, vol. 12, no. 4, pp. 332-336, 2000.

[37] S. J. Ott, M. Musfeldt, K. N. Timmis, J. Hampe, D. F. Wenderoth, and S. Schreiber, "In vitro alterations of intestinal bacterial microbiota in fecal samples during storage," Diagnostic Microbiology and Infectious Disease, vol. 50, no. 4, pp. 237245, 2004.

[38] S. J. Achá, I. Kühn, G. Mbazima, P. Colque-Navarro, and R. Möllby, "Changes of viability and composition of the Escherichia coli flora in faecal samples during long time storage," Journal of Microbiological Methods, vol. 63, no. 3, pp. 229-238, 2005.

[39] N. Klijn, A. H. Weerkamp, and W. M. de Vos, "Genetic marking of Lactococcus lactis shows its survival in the human gastrointestinal tract," Applied and Environmental Microbiology, vol. 61, no. 7, pp. 2771-2774, 1995.

[40] J. H. A. Apajalahti, L. K. Särkilahti, B. R. E. Mäki, J. P. Heikkinen, P. H. Nurminen, and W. E. Holben, "Effective recovery of bacterial DNA and percent-guanine-plus-cytosine-based analysis of community structure in the gastrointestinal tract of broiler chickens," Applied and Environmental Microbiology, vol. 64, no. 10, pp. 4084-4088, 1998.

[41] J. Gong, R. J. Forster, H. Yu, et al., "Diversity and phylogenetic analysis of bacteria in the mucosa of chicken ceca and comparison with bacteria in the cecal lumen," FEMS Microbiology Letters, vol. 208, no. 1, pp. 1-7, 2002.

[42] S. Peuranen, K. Tiihonen, J. Apajalahti, A. Kettunen, M. Saarinen, and N. Rautonen, "Combination of polydextrose and lactitol affects microbial ecosystem and immune responses in rat gastrointestinal tract," British Journal of Nutrition, vol. 91, no. 6, pp. 905-914, 2004.

[43] J. Dicksved, J. Halfvarson, M. Rosenquist, et al., "Molecular analysis of the gut microbiota of identical twins with Crohn's disease," ISME Journal, vol. 2, no. 7, pp. 716-727, 2008.

[44] T. G. Egwang and J. O. D. Slocombe, "Evaluation of the Cornell-Wisconsin centrifugal flotation technique for recovering trichostrongylid eggs from bovine feces," Canadian Journal of Comparative Medicine, vol. 46, no. 2, pp. 133-137, 1982. 
[45] E. Kikuchi, Y. Miyamoto, S. Narushima, and K. Itoh, "Design of species-specific primers to identify 13 species of Clostridium harbored in human intestinal tracts," Microbiology and Immunology, vol. 46, no. 5, pp. 353-358, 2002.

[46] C. R. Jackson, P. J. Fedorka-Cray, and J. B. Barrett, "Use of a genus- and species-specific multiplex PCR for identification of enterococci," Journal of Clinical Microbiology, vol. 42, no. 8, pp. 3558-3565, 2004.

[47] S. Cheng, F. K. McCleskey, M. J. Gress, et al., "A PCR assay for identification of Enterococcus faecium," Journal of Clinical Microbiology, vol. 35, no. 5, pp. 1248-1250, 1997.

[48] Z. Shen, Y. Feng, and J. G. Fox, "Identification of enterohepatic Helicobacter species by restriction fragment-length polymorphism analysis of the 16S rRNA gene," Helicobacter, vol. 5, no. 3, pp. 121-128, 2000.

[49] R. O. Elder, G. E. Duhamel, M. R. Mathiesen, E. D. Erickson, C. J. Gebhart, and R. D. Oberst, "Multiplex polymerase chain reaction for simultaneous detection of Lawsonia intracellularis, Serpulina hyodysen teriae, and Salmonellae in porcine intestinal specimens," Journal of Veterinary Diagnostic Investigation, vol. 9, no. 3, pp. 281-286, 1997.

[50] W. Kraatz, U. Thunberg, B. Pettersson, and C. Fellström, "Human intestinal spirochetosis diagnosed with colonoscopy and analysis of partial 16S rDNA sequences of involved spirochetes," Animal Health Research Reviews, vol. 2, no. 1, pp. 111-116, 2001.

[51] T. Rinttilä, A. Kassinen, E. Malinen, L. Krogius, and A. Palva, "Development of an extensive set of 16S rDNA-targeted primers for quantification of pathogenic and indigenous bacteria in faecal samples by real-time PCR," Journal of Applied Microbiology, vol. 97, no. 6, pp. 1166-1177, 2004.

[52] I. U. H. Khan, V. Gannon, R. Kent, et al., "Development of a rapid quantitative PCR assay for direct detection and quantification of culturable and non-culturable Escherichia coli from agriculture watersheds," Journal of Microbiological Methods, vol. 69, no. 3, pp. 480-488, 2007.

[53] O. Firmesse, S. Rabot, L. G. Bermúdez-Humarán, G. Corthier, and J.-P. Furet, "Consumption of Camembert cheese stimulates commensal enterococci in healthy human intestinal microbiota," FEMS Microbiology Letters, vol. 276, no. 2, pp. 189-192, 2007.

[54] P. J. D. Lambshead, C. J. Brown, T. J. Ferrero, L. E. Hawkins, C. R. Smith, and N. J. Mitchell, "Biodiversity of nematode assemblages from the region of the Clarion-Clipperton Fracture Zone, an area of commercial mining interest," BMC Ecology, vol. 3, article 1, pp. 1-12, 2003.

[55] P. M. Perrin, J. R. Martin, S. J. Barron, and J. R. Roche, "A cluster analysis approach to classifying Irish native woodlands," Biology and Environment, vol. 106, no. 3, pp. 261-275, 2006.

[56] S. Waite, Statistical Ecology in Practice, Pearson Education, Harlow, UK, 2000.

[57] M. Marzorati, L. Wittebolle, N. Boon, D. Daffonchio, and W. Verstraete, "How to get more out of molecular fingerprints: practical tools for microbial ecology," Environmental Microbiology, vol. 10, no. 6, pp. 1571-1581, 2008.

[58] S. L. Collins, F. Micheli, and L. Hartt, "A method to determine rates and patterns of variability in ecological communities," Oikos, vol. 91, no. 2, pp. 285-293, 2000.

[59] F. M. Ausubel, R. Brent, and R. E. Kingston, Current Protocols in Molecular Biology, vol. 1, John Wiley \& Sons, Hoboken, NJ, USA, 1997.
[60] J. P. Heath, "Erratum: quantifying temporal variability in population abundances (Oikos (2006) 115 (573-581))," Oikos, vol. 116, no. 3, p. 540, 2007.

[61] M. Rossi, M. L. Hänninen, J. Revez, M. Hannula, and R. G. Zanoni, "Occurrence and species level diagnostics of Campylobacter spp., enteric Helicobacter spp. and Anaerobiospirillum spp. in healthy and diarrheic dogs and cats," Veterinary Microbiology, vol. 129, no. 3-4, pp. 304-314, 2008.

[62] R. B. Sartor, "Therapeutic manipulation of the enteric microflora in inflammatory bowel diseases: antibiotics, probiotics, and prebiotics," Gastroenterology, vol. 126, no. 6, pp. 1620-1633, 2004.

[63] D. N. Frank, A. L. St. Amand, R. A. Feldman, E. C. Boedeker, N. Harpaz, and N. R. Pace, "Molecular-phylogenetic characterization of microbial community imbalances in human inflammatory bowel diseases," Proceedings of the National Academy of Sciences of the United States of America, vol. 104, no. 34, pp. 13780-13785, 2007.

[64] A. Swidsinski, J. Weber, V. Loening-Baucke, L. P. Hale, and H. Lochs, "Spatial organization and composition of the mucosal flora in patients with inflammatory bowel disease," Journal of Clinical Microbiology, vol. 43, no. 7, pp. 3380-3389, 2005. 


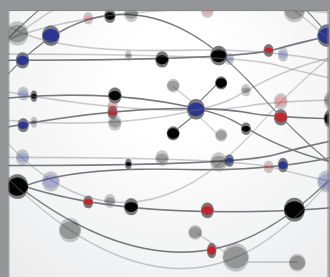

The Scientific World Journal
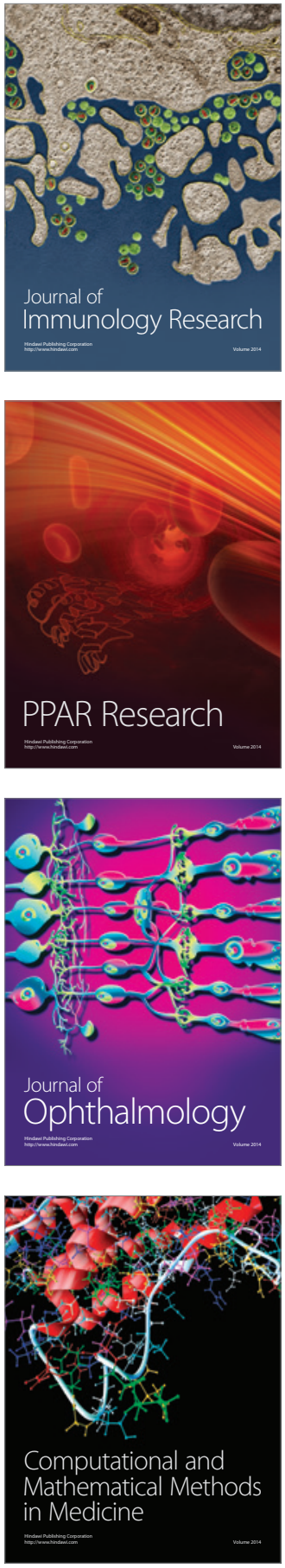

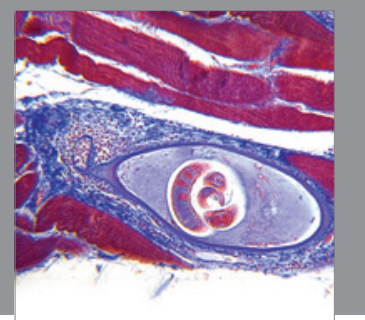

Gastroenterology

Research and Practice
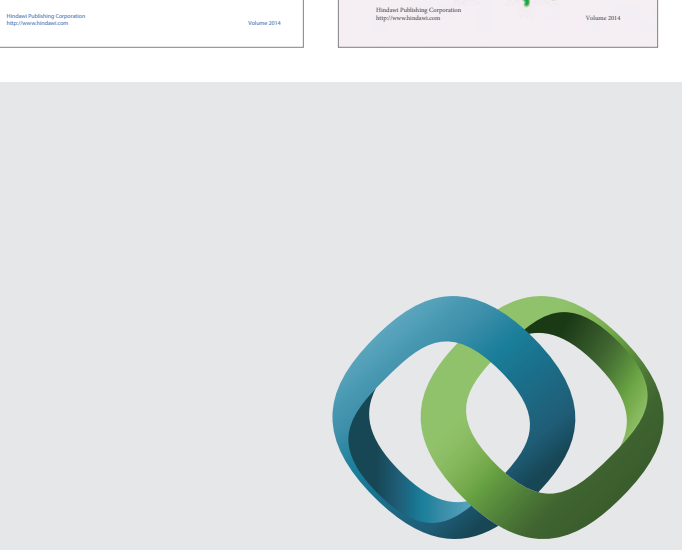

\section{Hindawi}

Submit your manuscripts at

http://www.hindawi.com
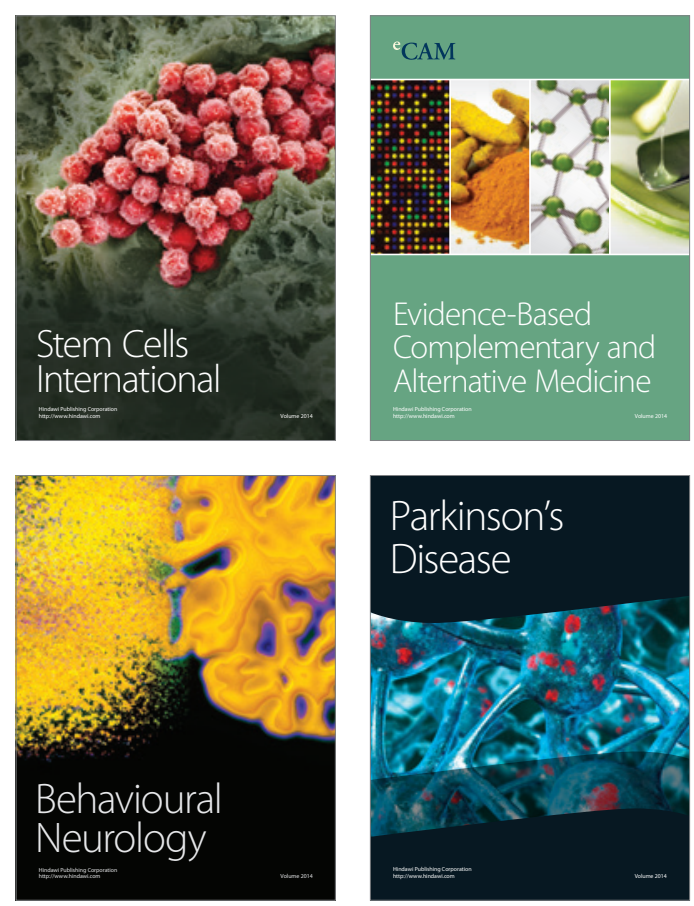

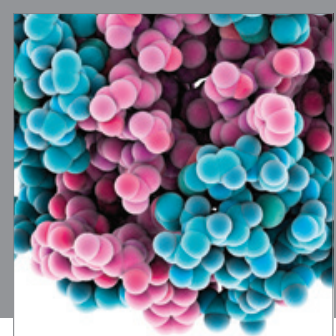

Journal of
Diabetes Research

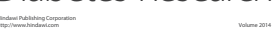

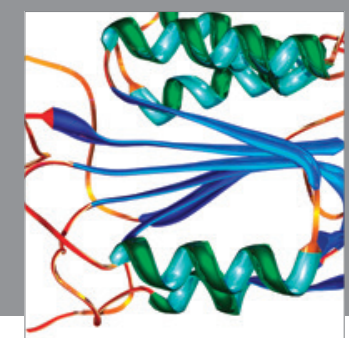

Disease Markers
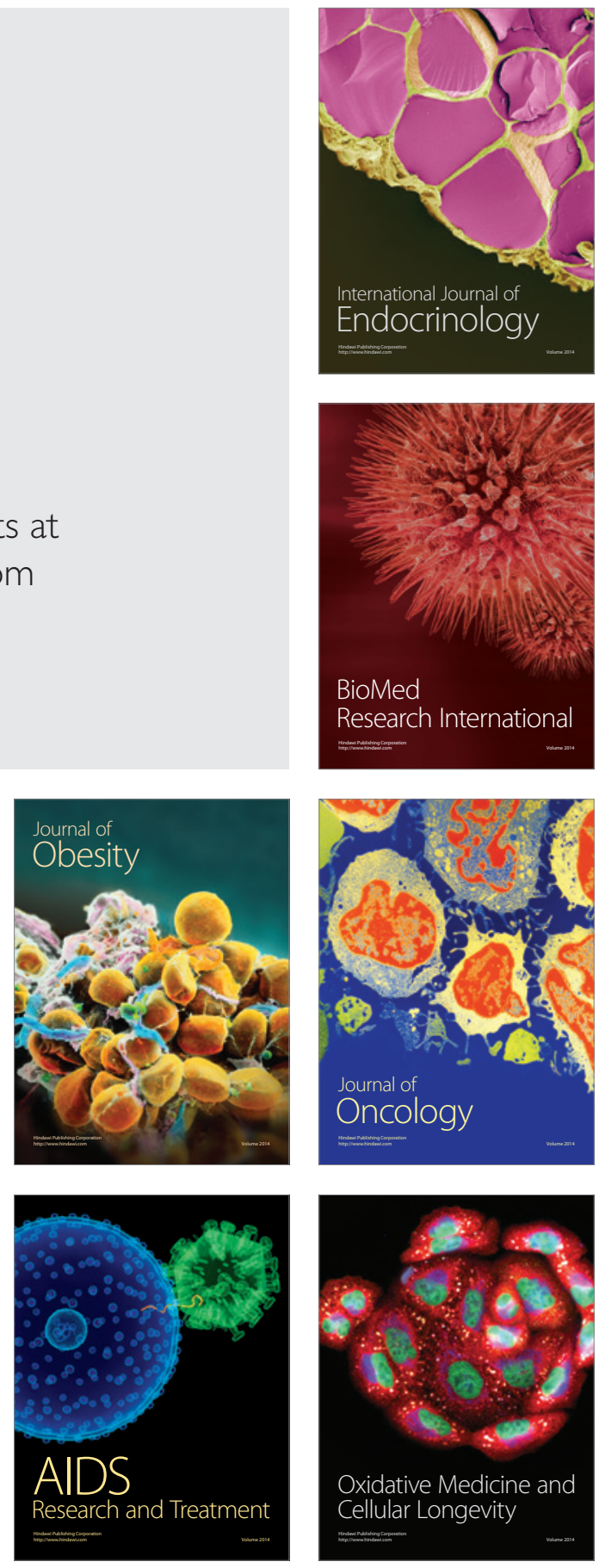